\title{
Los Patronatos de Laicos en la crisis del Antiguo Régimen: el Señorío de Vizcaya
}

\author{
Jesús María Pitarque de la Torre
}

\begin{abstract}
RESUMEN
ABSTRACT

En julio de 1844, varios patronos de iglesias de Vizcaya, amparándose en

el Fuero de Vizcaya, reclamaban el restablecimiento del pago de los diezmos. Invocaban al «sagrado derecho de propiedad", a la religiosidad del pueblo vizcaíno y a razonamientos propios de una mentalidad aristocrática difícil de superar. La evolución de los patronatos de laicos en Vizcaya durante la primera mitad del siglo XIX revela la pervivencia de instituciones del Antiguo Régimen en el tránsito a una sociedad liberal moderna.

PALABRAS CLAVES Patronato de Laicos, Patronatos Diviseros, Patronatos Realengos, Patronato Real, Diezmos, Iglesia propia, Establecimiento de expósitos, Iglesia, Vizcaya, Fuero de Vizcaya.

In July of 1844, several patrons of Biscay Churches, protected by the Biscay Law, demanded the restoration of the tithe. They invoked "he sacred right to property", the religious of people of Biscay and a reasoning characteristic of an aristocratic mentality, hard to overcome. The evolution of the Patronage of Laymen in Biscay during the first part of $X I X$ century, reveals the continuation of institutions of the Old Regime in the transit to a modern liberal society.

KEYWORD

Lay Patronage, Royal Patronage, Tithe, Lay Tithe, Biscay, Biscay Law-code, Own Church.
\end{abstract}




\section{INTRODUCCIÓN}

El estudio de una institución del Antiguo Régimen como el Patronato de laicos, durante su fase final en el tránsito hacia la sociedad liberal moderna, es un objetivo tremendamente ambicioso para tratar de abordarlo en un trabajo de las características del presente. Sin embargo, esta pequeña aproximación al tema carecería de sentido sin plantearse seriamente tal objetivo. Es por ello por lo que, aun sin renunciar al mismo, es indispensable fijar unas metas más asequibles y por lo tanto mucho más modestas, sobre las cuales en el futuro se pueda ir construyendo el complejo estudio de la evolución de una institución de remotos orígenes, cuyas pervivencias han llegado casi hasta nuestros días. No se pretende por tanto sacar ninguna conclusión, por pequeña que ésta sea, sobre un asunto de tanta complejidad, aplazando deliberadamente cualquier interpretación a estudios posteriores y a las aportaciones de estudiosos más autorizados que el autor de estas líneas.

Un primer objetivo que se ha pretendido alcanzar es el de recopilar las fuentes documentales y la bibliografía relacionada con el tema de los patronatos laicos en las iglesias españolas, y en particular en las de Vizcaya, así como realizar una aproximación a las fuentes documentales de primera mano. Un segundo objetivo ha sido el de organizar las referencias documentales de tal forma que puedan constituir una herramienta de trabajo para una futura investigación en profundidad. Finalmente, lo que pretende este trabajo es, tal como se indica en su título, acercarse a las vicisitudes de los patronatos laicos en Vizcaya durante la crisis del Antiguo Régimen, buscando aquellos hitos más significativos que, enmarcados en un contexto general, pueden constituir elementos clave para la comprensión del fenómeno de la pervivencia, si no de la institución como tal sí de algunas de sus prerrogativas, durante gran parte del siglo XIX y en algunos casos incluso durante el siglo $x x$.

La pervivencia de instituciones del Antiguo Régimen y su evolución durante el desarrollo de las sociedades liberales del siglo XIX revela la evidencia de la inexistencia de una ruptura total, tal como se manifiesta en las tesis de Arno Mayer. En la lucha entre las estructuras e instituciones de las antiguas sociedades estamentales basadas en los privilegios y las nuevas sociedades que comienzan a configurarse basadas en conceptos como el mérito, el trabajo y la propiedad, éstas terminarán por triunfar, pero no de la misma manera, ni en el mismo momento en todos los lugares. En algunos casos, la fuerza de determinadas instituciones, el poder de quienes las representan y se benefician de ellas, las estructuras sociales que las amparan y defienden, ha permitido que instituciones del Antiguo 
Régimen pervivan aún en nuestras sociedades, en las puertas del siglo $\mathrm{XXI}$.

Dentro del marco general definido y con la vista puesta en los objetivos señalados, este trabajo tratará de establecer las bases metodológicas y documentales y los puntos de partida para el posterior desarrollo de una investigación desde el punto de vista histórico sobre los Patronatos de laicos en la crisis del Antiguo Régimen. Para ello se han estudiado los antecedentes de dicha institución, su situación particular en las iglesias de Vizcaya, la legislación foral referente a la misma y las bases jurídicas en las que se sustentaba. Así mismo se ha tratado de conocer los pleitos que tuvieron lugar, que revelan los intereses encontrados en muchas ocasiones entre los reyes, los patronos, los cabildos eclesiásticos, los obispados y el pueblo, que era quien, en definitiva, sostenía la institución con los diezmos. Se han estudiado las prerrogativas de quienes detentaban los patronatos y el poder que les otorgaba, quiénes eran los patronos y cuáles eran sus relaciones con el poder político y con la jerarquía eclesiástica. Por último se han analizado las vicisitudes por las que pasó dicha institución durante los últimos siglos y sobre todo durante la primera mitad del siglo XIX, ya que esta época es la que constituye el ámbito temporal de este trabajo. Con el fin de realizar una aproximación al poder social de los patronos laicos se ha realizado un estudio de la «geografía» de los patronatos, de sus titulares y de sus prerrogativas, y de las rentas obtenidas por los mismos ${ }^{1}$.

\section{FUENTES PARA EL ESTUDIO DE LOS PATRONATOS LAICOS}

Son bastante escasos los estudios existentes sobre patronatos, especialmente los estudios realizados desde un punto de vista histórico, ya que son más abundantes los de tipo jurídico. Sin embargo, todos ellos hacen re-

En el Anexo I se incluye una tabla detallada de los patronatos de todas las iglesias de Vizcaya. Los titulares de los patronatos se han obtenido de los expedientes formados en 1810 como consecuencia de la Orden del Gobernador de Vizcaya, General Thouvenot, del 2 de agosto de 1810, por la que se requería a los Consejos Municipales y a los Cabildos de las iglesias de Vizcaya el envío de informes sobre la situación de los patronatos, sus poseedores y los títulos de los mismos (AFB-A,ORGFB, Caja 168). Los rendimientos mensuales que figuran en la tabla se han obtenido a partir del reparto del $4 \%$ sobre la mitad def líquido producto de los diezmos de los patronos de Vizcaya realizado por la Comisión de Patronos formada a instancias de la Diputación con el fin de recaudar una contribución extraordinaria impuesta a los patronos de Vizcaya (AFB-A, CC, Reg. 15, leg. 5). Los rendimientos de 1837 son los obtenidos por el embargo realizado por la Diputación carlista (AFB-A, PA, Reg. 2, leg. 14). 
ferencia a la institución del Patronato durante el Antiguo Régimen y no se ha encontrado ninguno que aborde el estudio de su etapa final.

La tesis doctoral de Ángel Larrea Beobide «El patronato de laicos en la Vizcaya del Antiguo Régimen", aporta información abundante sobre los orígenes de la institución, características y tipología, y realiza un minucioso estudio histórico de su evolución a lo largo de la Edad Media y de la Edad Moderna, llegando hasta comienzos del siglo XIX. Es probablemente el estudio más completo existente sobre los patronatos de laicos en Vizcaya, pero no aborda la evolución de esta institución durante el siglo XIX. También sobre los patronatos en Vizcaya, se ha consultado un artículo en el que se recogen algunos datos de interés para la comprensión de los orígenes del patronato: Adolfo Lafarga Lozano, "Los Patronatos y Prebostadas del Real Patrimonio en Vizcaya en 1416», en La Gran Enciclopedia Vasca, tomo II, Bilbao, 1966.

Aunque no directamente relacionado con el tema de los patronatos laicales, aporta una información de gran interés: Ricardo Montolío Hernández, «El medio diezmo. Un episodio en la reforma eclesiástica del trienio liberal (1820-1823)», en Hispania Nova, 1999, ya que la reducción del diezmo durante el trienio tuvo repercusiones sobre los partícipes laicos del mismo para quienes se estableció un sistema de indemnizaciones que dio lugar a numerosos conflictos. Este artículo es un extracto de su tesis "Culto y Clero: el mediodiezmo", a la que no he tenido acceso. Del mismo autor: Ricardo Montolío Hernández, «La reforma de la dotación de culto en el trienio liberal (1820-1823)» ponencia presentada en el Curso de verano de la UNED La Iglesia española y la crisis del Antiguo Régimen, 1999, también aporta algunos datos de interés. En relación con la situación del diezmo durante el siglo XIX y su supresión definitiva: José María Ortíz de Orruño, «Religión y política en el País Vasco (1839-1876)», ponencia presentada en el Curso de verano de la UNED La Iglesia española y la crisis del Antiguo Régimen, 1999; Esteban Canales, «El diezmo a fines del Antiguo Régimen» en La economía española al final del Antiguo Régimen, dirigida por Gonzalo Anes, Alianza Universidad, Madrid, 1982. Estudios más generales o incluso relacionados con otros temas, pero que aportan algunos datos en relación con el tema aquí estudiado son: Francisco Fernández Pardo, La independencia vasca. La disputa sobre los fueros, Madrid, 1990; Alfonso de Otazu y Llana, El igualitarismo vasco: mito y realidad, San Sebastián, 1986; Fernando García de Cortazar y Manuel Montero, Historia de Vizcaya, San Sebastián, 1994.

Desde el punto de vista jurídico las fuentes bibliográficas más importantes, algunas de las cuales han sido consultadas para la elaboración de 
este trabajo, aunque otras se recogen como mera referencia, son: $\mathrm{R}$. Bidagor, La lglesia propia en España, Roma, 1953; Antonio Bravo y Tudela, El Derecho vigente sobre Capellanías Colativas de sangre, beneficios y legados pios, patronatos laicales y fundaciones de la propia índole, Madrid, 1879; Pedro Benito Golmayo, Instituciones del Derecho Canónico, Madrid, 1896, en el que se estudian los patronatos desde el punto de vista del derecho canónico, aportando gran cantidad de información acerca de sus diferentes clases, sus prerrogativas, la forma de ejercerlas y la justificación de las mismas; Adolfo Lafarga, "Noticia de los Reales Patronatos del Señorío de Vizcaya" en Hidalguía, n. ${ }^{\circ} 103$, 1970; Juan Antonio Llorente, Discursos histórico-canónicos sobre los beneficios patrimoniales de las iglesias parroquiales de los obispados de Calahorra y La Calzada, Pamplona, 1789, pequeña obra, muy polémica, que Llorente escribió en defensa de los derechos del obispo de Calahorra y La Calzada en relación con la presentación de beneficiados en las iglesias de la diócesis; M. Ros, Historia de las rentas de la Iglesia de España, Madrid, 1793; J. San Martín, El diezmo eclesiástico en España hasta el siglo XII, 1940; J. Sempere, Historia de las rentas eclesiásticas de España, Madrid, 1822; M. Torres López, "La doctrina de las iglesias propias en los autores españoles» en Anuario de Historia del Derecho español, 1925; Joseph de Vinuesa, Diezmo de legos en las iglesias de España, Madrid, 1791; Fournier, «La propriété des églises dans les premiers siècles du moyen âge» en Nouvelle Revue Historique de Droit francais \& étranger, 1897; Thomas, Le Droit de propriété de laiques sur les églises et le patronage laique au moyen âge, Paris, 1906; V. Stutz, Das Eigenkirchenrecht, Berlín, 1895.

Finalmente, aunque no directamente relacionadas con el estudio de los patronatos, las siguientes obras aportan información de gran interés para su estudio: Joseba Agirreazkuenaga y otros, Diccionario biográfico de los Diputados Generales, burócratas y patricios de Bizkaia (1800-1876), Bilbao 1995, y Joseba Agirreazkuenaga y otros, Diccionario biográfico de los parlamentarios de Vasconia, Vitoria, 1993, en los que se han consultado datos biográficos de varios de los patronos laicos estudiados; también de relativo interés para el conocimiento de datos biográficos el libro Grandezas y Títulos del Reino. Guía Oficial, Ministerio de Justicia, Madrid, 1958; José Canga Argüelles, Diccionario de Hacienda, Madrid, 1833; José María de Estecha y Martínez, Régimen político y administrativo de las provincias vascongadas, Bilbao, 1918, que cuenta con una importante colección de documentos legales relativos a las provincias vascongadas; Manuel Garzón Pareja, Historia de la Hacienda de España, Madrid, 1984; Historia de la Iglesia en España dirigida por Ricardo García Villoslada, Madrid, 1979. Así mismo, una aportación fundamental para el conocimiento de los 
patronatos en Vizcaya la constituye el Fuero, privilegios, franquezas y libertades del Muy Noble y Muy Leal Señorío de Vizcaya, conocido como «El Fuero de 1526», cuyo título 32 trata De los Patronazgos y Jueces Eclesiásticos y Fiscales.

Sin embargo, el mayor aporte de fuentes documentales, con las que se ha trabajado para la elaboración de este estudio, se ha conseguido en el Archivo Foral de Bizkaia, en la sección Administrativo, en cuyos fondos se ha encontrado una abundante documentación relacionada con diversas pesquisas realizadas sobre los patronatos realengos y diviseros de Vizcaya, con los planes beneficiales, con informes variados sobre patronatos, pleitos, adjudicación de patronatos reales, requisitorias para la presentación de títulos, embargos y secuestros, circulares, órdenes y decretos de la Diputación foral y de la Diputación provincial y Reales Órdenes relacionadas con el mismo asunto, remates de diezmos, contribuciones extraordinarias sobre diezmos, etc. No se han consultado, debido al alcance limitado de este trabajo, otros archivos como el Archivo Eclesiástico de Vizcaya, el diocesano del obispado de Calahorra y La Calzada, el Archivo de la diócesis de Vitoria y el Archivo Histórico Nacional. En el Archivo Foral de Bizkaia (AFB), en la sección Administrativo, se han consultado los siguientes fondos: Patronatos, Culto y Clero, Órganos y Régimen de Gobierno, Fondo Balparda, Contribuciones, Diputación General, Juntas Generales de Guernica (manuscritas), Bienes Secuestrados y Embargados, Congruas Beneficiales, Libros Históricos y Órdenes y Circulares de la Diputación.

De gran utilidad para la localización de los documentos existentes en el fondo denominado Juntas Generales de Guernica (manuscritas) del Archivo Foral de Bizkaia, todos ellos relativos a actas de Juntas Generales, Diputación General y Regimiento General, ha sido el catálogo realizado bajo la dirección de M. ${ }^{a}$ Ángeles Larrea Sagarminaga y Rafael M. ${ }^{a}$ Mieza y Mieg, publicado por la Diputación Foral de Bizkaia y la Univerșidad de Deusto en 1992, con el título Legislación Foral del Señorío de Vizcaya (1528-1877). Las Reales Órdenes, Cédulas, Circulares, Decretos, etc... se han consultado en: José María Estecha y Martínez, Régimen político y administrativo de las provincias vascongadas, Bilbao, 1935; en la Colección de leyes y decretos (1814-1876) y en los Diarios de las actas y discusiones de las Cortes de los años 1820, 1821 y 1822 2.

\footnotetext{
2 En los Diarios de las Cortes de los años 1820, 1821 y 1822 se encuentran interesantísimos debates sobre las bases propuestas por la comisión para establecer un plan fijo de hacienda, en
} 


\section{LLEVADORES DE DIEZMOS Y PATRONATOS DIVISEROS $Y$ REALENGOS}

Frecuentemente se confunden las diferentes clases de patronatos entre sí, y estos con los perceptores de diezmos. No todos los perceptores de diezmos poseían títulos de patronato, ya que en muchos casos los perceptores de diezmos no eran más que simples arrendatarios de los mismos, los cuales habían adquirido dicho derecho por medio de un contrato de arrendamiento ${ }^{3}$. En numerosas ocasiones los diezmos incluso se subarrendaban. Todas las cargas inherentes a los diezmos, noveno, tercias, excusado, subsidio, etc., solían correr de cuenta del arrendatario. Por otra parte, las escrituras de arrendamiento de diezmos aportan una información de gran valor para evaluar la riqueza de los pueblos y el poder económico de los patronos ${ }^{4}$.

los que se aborda la problemática de la reducción del diezmo. Concretamente en los diarios del 13 y 14 de octubre de 1820 se debate sobre la base $2 .^{\text {a }}$ del mencionado plan relativa a la modificación del diezmo. En un momento del debate, el Diputado Sr. Priego, en clara alusión a los diezmos percibidos por laicos, dice: « ¿los diezmos que pagan los pueblos a los duques, grandes y marqueses son precio del trabajo espiritual, que como operarios de la casa del Señor, o como bueyes que trillan en la era de su iglesia (alude a los razonamientos del Sr. Lobato) les ha sido concedido por el mismo Dios?... ... Señor, me exalto cuando se llega a esta materia, pero no puedo remediarlo. Los diezmos son, se dice, de derecho natural y divino cuando se trata de que los perciban los duques y los canónigos, pero con respecto a los curas no son ni de derecho eclesiástico. Hay obispados en donde los curas no tienén parte alguna en diezmos..." (DSC, 13 de octubre de 1820, pag.35).

3 Los patronatos reales se solían sacar a remate, tal como consta, de los pregones realizados en 1416, en la transcripción de varios documentos relativos a los patronatos del Señorío de Vizcaya que se hizo en la pesquisa de 1708, hecha por orden de S. M., en donde se dice textualmente: «Relacion de Monasterios y Oficios que el Rey tiene en Vizcaya= Pregones que se dieron a los bienes año de mill quatrocientos y diez y seis= Primeramente pregonan la Merindad de Durango que tiene Juan de Mujica que tiene en ella de situado mill y quinientos marabedis si hay quien de mas por ella mill y quinientos= Item...» (AFB-A, PA, Reg. 1, leg. 11, folio 6v.). Habría que averiguar si en estos casos el rematante adquiría todas las prerrogativas y derechos inherentes al patronato, o simplemente adquiria el derecho al cobro de los diezmos correspondientes.

4 En 1832, un vecino de Vedia remató para tres años los Diezmos de Santa María de Lemona, cuyos patronos eran los Condes de Chinchón. Según la copia de la escritura de remate, éste se realizó para tres años, en la cantidad de 9.240 reales de vellón en cada año, que el rematante, Don José de Sorriqueta, debería abonar en dos plazos anuales al administrador de los Condes de Chinchón. Hay que tener en cuenta que, tal como se menciona en la citada escritura, «... será de cuenta y cargo del rematante la entrega en grano al Cavildo Eclesiástico de dicha Anteiglesia de Lemona de 32 fanegas de trigo y 24 fanegas de maíz en sus respectivas casas en cada uno de dichos tres años= Que igualmente será de cuenta y cargo del rematante la satisfacción a dichos señores del Cabildo Eclesiástico de 324 reales en dinero efectivo según costumbre por el derecho llamado del tocino y manzana en cada uno de los tres indicados años= Que así mismo será de cuenta y cargo del rematante la satisfacción del RI. Noveno y Casa Excusada, así como también la contribución anual del Seminario Conciliar..." (AFB-A, PA, Reg. 2, leg. 14). Según algunos expedientes del año 1834, como el de San Andrés de Echevarría (AFB-A, CC, Reg. 15, leg. 7), podemos saber que el precio de una fanega de trigo era de 33 reales y el de una de maíz 22 reales, por lo que resulta que la dotación anual al Cabildo de Lemona ascendería a 1.908 reales de vellón. 
La percepción de los diezmos era uno más de los derechos de los patronos, quienes también tenían obligaciones. Entre los derechos se encontraban, además del de la percepción de los diezmos ${ }^{5}$, y de otros derechos honoríficos como la posesión de asiento preeminente en la iglesia, el de la presentación de Beneficios. Este último derecho es propio de los patronos y es quizá el que les otorgaba a éstos un mayor poder de control social, además de permitirles colocar como beneficiados a sus propios parientes. Entre las obligaciones de los patronos estaba el mantenimiento de los beneficiados, el pago de los subsidios establecidos para el clero, el noveno y las tercias reales, y el mantenimiento de las fábricas de las iglesias y la necesaria dotación para el mantenimiento de los ornamentos y de los vasos sagrados. Estas obligaciones, que no siempre se cumplían de la forma más conveniente, fueron el origen de numerosos pleitos y conflictos entre los patronos y los cabildos.

En Vizcaya, los patronatos se dividían en dos clases: patronatos reales o de realengo y patronatos diviseros o deviseros ${ }^{6}$. A pesar de que Juan Antonio Llorente, en sus Discursos Histórico-Canónicos sobre los Beneficios Patrimoniales..., anteriormente citados, señala que «Todas las Iglesias de España son de el Real Patronato ${ }^{7}$ basando su afirmación en la ley 18 , partida 1, tit. 5 de Las Partidas, Don Pedro Benito Golmayo en su obra Instituciones del Derecho Canónico, afirma que una de las maneras en las

Por lo tanto, lo que obtenía el patrono era casi cinco veces la dotación asignada al Cabildo, y como se supone que el señor Sorriqueta también ganaría algo, podemos considerar que los rendimientos económicos de los patronatos no eran nada despreciables. Por otra parte, teniendo en cuenta que Lemona, según el Diccionario Geográfico-Histórico de España editado por la Real Academia de la Historia en Madrid en 1802, tenía una población de tan solo 636 almas, se puede evaluar también la presión económica que suponía el diezmo para los agricultores.

5 La percepción de los diezmos por parte de los patronos podría tener un remoto origen en el conducho o yantar, prestación que antiguamente debía pagar el vasallo a su señor en forma de provisiones o bagajes.

6 Devisa, según el Diccionario enciclopédico Espasa, Especie de señorío que tenían en Castilla los hijosdalgo sobre las tierras heredadas de sus padres y ascendientes, y que habían dividido (de ahí el nombre) entre sí, como hermanos, conservándose en ellas. Los moradores de estas tierras eran vasallos solariegos de los deviseros. Sin embargo, en la exposición que hicieron al rey don Juan I, los señores patronos de la iglesias de Vizcaya, Guipúzcoa y Álava, en defensa de sus derechos, ante la reclamación efectuada en las Cortes de Guadalajara, en 1390, por los obispos de varias diócesis, entre ellas Pamplona y Calahorra, se da la siguiente explicación del significado de devisa y de devisero: «... e aún hoy día son tenidos los tenedores de los dichos diezmos quando alguno de aquellos Linajes que otorgaron los tales diezmos viniere a su casa de le recibir bien, e le dar a comer una vez en el año con aquella campaña que de cada día suele traer; lo cual llaman devisa, e el tal dicen devisero de la lglesia; salvo si aquel a quien la tal divisa pertenesce la vende, ca la puede vender segund la costumbre que entre sí obieren..." (citado por Adolfo Lafarga, Los Patronatos y Prebostadas..., 1966).

7 LLORENTE, pag. 94. 
que se adquiere el derecho de patronato es mediante la fundación cle una iglesia, siempre que incluya «la donación de un fundo en que se edifique, la construcción del templo y la dotación » ${ }^{8}$. En este hecho se basan los patronatos diviseros existentes en Vizcaya. Un caso concreto se encuentra en el memorial presentado en 1802 por un representante de los patronos "diviseros" de la Anteiglesia de Elexabeitia, en el que trata de justificar que su patronato es divisero y por lo tanto que les pertenece, no pudiéndose considerarse éste como usurpado a la Corona. Tras exponer la consideración de su patronato como divisero: «... Digo que el Patronato del Monasterio de San Miguel de Elexabeitia es uno de los dibiseros, e debisas que de antiguamente aca tubieron y posehieron los vizcainos, e homes Hijos-dalgo, auttores de mis principales, consintiendolo, e apremiandolo, todos los Santos Padres de Roma, los Reyes y Principes de España y por lo mismo conforme a las leies primera y segunda titulo treinta y dos de los Fueros de este ilustre Solar...», se presentan los argumentos de fundación mencionados por Golmayo: «... ademas concurre que el citado Monasterio se halla edificado en terreno propio y pribatibo de la dha casa torre sin que en un palmo de tierra se hubiere tocado a suelo de tercero... ... que jamás se ha contribuido por la Corona, ni quien la represente con maravedi alguno para el edificio material... ni ornamentos... porque todo se ha suplido y suple por los posehedores de dha casa torre que estos mismos han probeido y preveen en las bacantes el unico titulo de Beneficio..." ".

El propio Fuero de Vizcaya, en su Título 32 , Ley $1 .{ }^{a}$, reconoce la existencia de los dos tipos de patronatos: "Que habían de fuero y establecían por Ley que por cuanto en Vizcaya hay Monasterios de Patronazgos, de ellos de patronazgo real, y de ellos deviseros, y devisas que de antiguamente aca...", y en la Ley 2.a: "... que por cuanto todos los Monasterios y patronazgos de Vizcaya siempre los tuvieron, y tienen, los vizcaínos y hombres hijosdalgo de ella, los unos de Su Alteza y los otros de los deviseros.... ${ }^{10}$. Parece claro por lo tanto la existencia, reconocida por diferentes instancias, de los dos tipos de patronatos. Otro problema es saber

8 GOLMAYO, pag. 249. Los medios por los que se adquiere el derecho de patronato, con el correspondiente derecho de presentar Beneficios, los recoge Golmayo de la Ley I, part. I, tit. 15 de Las Partidas en donde se dice que este derecho se adquiere por tres razones «La una por el suelo que da a la Eglesia en que la facen, La segunda porque la facen. La tercera por heredamiento que le da...».

9 AFB-A, PA, Reg. 1, leg. 12.

10 El Fuero, Privilegios, Franquezas y Libertades del M. N. y M. L. Señorío de Vizcaya. Fuero de 1526. Título 32 . 
cuáles son de un tipo y cuáles del otro, siendo esta cuestión el origen de numerosos pleitos y de diversas pesquisas tendentes a descubrir los patronatos usurpados a la Corona y a solicitar los títulos de posesión.

La principal confusión entre las dos clases de patronatos deriva del hecho de que los reyes concedían los patronatos reales, es decir aquellos que pertenecían a la Corona, como merced y como juro de heredad por una o varias vidas a aquellos caballeros a quienes deseaban premiar por servicios prestados o a quienes querían mantener fieles. De esta forma el patronato, aunque continuase siendo realengo, era otra forma de patronato de laicos. La problemática en torno a estos patronatos es bastante compleja, ya que aunque, tal como lo expone Llorente, las mercedes otorgadas por los reyes no siempre lo fueron con las mismas condiciones. Parece ser que los reyes trataron de mantener para sí el derecho de presentación de Beneficios. Sin embargo, durante los reinados de Juan II y Enrique IV, debido al enorme poder que adquirió la aristocracia, parece ser que se concedieron numerosas mercedes con derecho de presentación de Beneficios, «de cuyas resultas, y de las otras antiguas gracias se suscitaron diferentes controversias sobre la pertenencia de esta prerrogativa...» 11 .

Se puede decir que en la totalidad de las Anteiglesias del Señorío existía una clase u otra de patronato. Sin embargo, en la villas, de las cuales hay veintiuna en Vizcaya, al tratarse de nuevas fundaciones, se daba una particularidad, ya que «En las Cartas Pueblas de las Villas se conceden generalmente los diezmos a los pobladores con la reserba de la tercera parte para los Señores de Vizcaya y Reyes que les sucedieren: Esta tercera parte se halla generalmente enajenada y concedida por juro de heredad con el nombre de prebostada, y en algunas las poseen las Iglesias y Clerigos, pero generalmente en todas las Villas se percibe la restante de la tercia parte por los Clerigos e Iglesia» ${ }^{12}$. Por tanto, nos encontramos con

11 LLORENTE, pag. 104.

12 AFB-A, CC, Reg, 14, leg. 2. Se trata de un expediente, de fecha 26 de octubre de 1810 , elaborado a partir de la documentación remitida por los Consejos Municipales y por los Cabildos de Vizcaya en respuesta a la Orden del Gobernador General Thouvenot. Hace una relación de todos los patronatos indicando de qué tipo son éstos y quien los posee y termina de la siguiente forma: "Estos son los patronatos que resultan= Ha sido imposible fijar a todos su naturaleza porque algunos expedientes se remitieron a la Camara y no han quedado mas que alguna diligencias imperfectas que no sirben para formar juicio= Por el Sr Rey Carlos Quarto se aplicaron a los niños expositos del Señorio de Vizcaya los Patronatos mercenarios vitalicios según fueren vacando, y ha entrado en posesion de algunos = Es comun en todos los Patronos Diviseros valerse de la posesion inmemorial, vinculaciones, sucesiones, sentencias en pleitos sobre si eran libres o vinculados, concordias con el Pueblo y Curas aprobadas por la RI. Camara sobre congrua y disputas con tal motibo...". 
más variantes. En las villas los llevadores de diezmos suelen ser la propia villa y los clérigos -la tercera parte-, aunque existen casos en los que se conceden a particulares con el nombre de prebostad.

\section{LOS PLEITOS RELACIONADOS CON LOS PATRONATOS}

La enorme complejidad que supone la existencia de diferentes clases de patronatos, cuya posesión en muchos casos era difícil de justificar, ya que normalmente no existían títulos de la misma y se aducía la posesión inmemorial, los títulos concedidos por los reyes en forma de mercedes por una o varias vidas, las transmisiones, los arrendamientos, todo ello era la causa de numerosos conflictos y pleitos que se desarrollaron a lo largo de toda la Edad Moderna y que continuaron durante el siglo XIX. La mayoría de estos pleitos permanecían durante decenas de años sin ser resueltos. Uno de los primeros pleitos conocidos fue el ocasionado por la reclamación de los obispos en las Cortes de Guadalajara en 1390 y que ya ha sido citado anteriormente.

Una de las causas de frecuentes pleitos elevados a la Real Cámara por la Diputación de Vizcaya, fue la concesión por merced real de patronatos realengos a personas no naturales del Señorío, ya que en el Fuero de Vizcaya, en la Ley VI de su Título primero, se dice: "Otrosí dijeron, que había de fuero, uso y costumbres, y por los Reyes de Castilla, como Señores de Vizcaya, les fue siempre guardado, y confirmado, y mandado guardar por privilegio, que todas las tierras, y mercedes, y monasterios, y oficios de Vizcaya su Alteza diese, e hiciese merced de ellas a los caballeros, escuderos, hijosdalgo naturales, y vecinos de Vizcaya, y Encartaciones, y merindad de Durango, y vacando por muerte del uno, hiciese merced de las tales tierras, e mercedes, e monasterios, e oficios a otro natural, e vecino del dicho Señorío, e no a otro alguno...” ${ }^{13}$. Según consta en las Actas manuscritas de las Juntas Generales, en varias ocasiones se produjeron quejas por cuanto se habían otorgado como merced real determinados patronatos a no naturales del Señorío. La concesión del patronato de la iglesia de Arrigorriaga al Marqués de Mejorada en 1694 fue seguida de repetidas protestas por parte de las Juntas Generales y de la Diputación en los años 1694, 1722, 1724 y 1732, año éste en el que finalmente las Juntas Generales celebradas el 24 de junio, acordaron cumplir

13 El Fuero, Privilegios, Franquezas y Libertades del M. N. y M. L. Señorío de Vizcaya. Fuero de 1526 . Título $1 .^{\circ}$, Ley VI. 


\section{j}

la Real Sobrecédula por la que se confirmaba el patronato de Arrigorriaga al Marqués de Mejorada ${ }^{14}$.

Ya en el siglo xIX, la Diputación seguía refiriéndose a la Ley VI del Título $1 .^{\circ}$ del Fuero para rechazar la concesión por merced real de patronatos a no naturales del Señorío, tal como lo hace en el memorial elevado a S. M. en solicitud de que se restituya al Establecimiento de Expósitos varios patronatos concedidos en 7 de diciembre de 1814 a Doña Josefa de Colón y Sierra ${ }^{15}$.

Sobre todo en las villas eran frecuentes los pleitos entre la Villa y los Cabildos Eclesiásticos, tanto en relación con la percepción de los diezmos como con la presentación de Beneficiados. Alguno de estos pleitos, iniciado durante el siglo XVIII, o incluso antes, continuaba sin ser resuelto en el siglo xix. Un ejemplo de estos pleitos es el existente entre el Cabildo Eclesiástico de la parroquial de Santiago de Bilbao y la villa. En este caso, las razones de unos y otros revelan, no sólo una lucha de intereses opuestos, sino incluso el enfrentamiento entre diferentes doctrinas de derecho canónico, dándose la circunstancia de que habitualmente el posicionamiento doctrinal de los Cabildos puede reputarse como más avanzado y más acorde con una sociedad moderna.

A raíz de la Real Orden del Supremo Consejo de la Cámara de fecha 31 de agosto de 1767, en la que se pedía que «sin retardación se informe... del valor anual de cada uno de los Patronatos Realengos que hay en el Señorío... y del estado en que se hallan las fábricas de sus respectivas iglesias... ${ }^{16}$, se suscitó un pleito entre el Cabildo Eclesiástico y la Villa de Bilbao como consecuencia de la representación que el alcalde ordinario de la villa remitió a la Cámara en 21 de agosto de 1778, pidiendo que "se le reintegrase en el derecho de presentar los Beneficios de sus Iglesias de que se le había despojado por el mismo Cabildo Ecco... ${ }^{17}$. Anteriormente, en 1773, el Cabildo había sido requerido por el Teniente General del Señorío, para que en cumplimiento de la citada Orden de 31 de agosto de 1767, presentase los títulos o privilegios que tuviese para la presentación de Beneficios y percepción de diezmos de las parroquias de la villa. En respuesta a este requerimiento, el Cabildo remitió, con fecha 18 de junio de 1773 , un escrito en

\footnotetext{
14 AFB-A, JGGM, Libro 28, Folio 99.

15 «Los Patronatos o Monasterios de Vizcaya según la ley $6 .^{a}$ Tit. $1 .^{\circ}$ de sus fueros confirmados por V.M. sólo se pueden dar por merced a sus naturales, de cuya calidad no goza Doña Josefa Colón...» (AFB-A, PA, Reg. 1, leg. 10).

is AFB-A, PA, Reg. 1, leg. 3.

17 AFB-A, PA, Reg. 1, leg. 3.
} 
el que se exponía la doctrina eclesiástica, también defendida en aquellos años por Juan Antonio Llorente en sus Discursos Histórico-Canónicos... ya mencionados. Según la opinión del Cabildo Eclesiástico de Bilbao, «su Cabildo siempre se ha mantenido con el derecho de presentar los Beneficios vacantes... y no hallan principio de ello ni necesitan título particular más que el que concede el derecho común canónico a todo Cabildo Eclesiástico... El derecho de dezmar es un derecho espiritual contraído por ministerio Eclesiástico y corresponden sus diezmos por ley de justicia a los ministros de la Iglesia en recompensa y remuneración del trabajo de administrar el pasto espiritual...» ${ }^{18}$. La defensa que hacía la villa de sus prerrogativas, en cambio, no aportaba ningún tipo de apoyo doctrinal, sino que se basaba fundamentalmente en el texto de la Carta Puebla de fundación de la villa, según la cual, como en el caso de las restantes villas del Señorío, los derechos de patronato fueron cedidos a la villa por real merced.

Sin embargo, en ningún lugar queda claro si la concesión de los patronatos reales por merced o gracia del monarca lleva implícito el derecho de presentación de beneficios. De hecho, en todos los casos se daba por supuesto tal derecho, ya que "para presentar los Beneficios es cosa esencial precisa y necesaria la qualidad de ser Patron lexitimo de la tal Iglesia» ${ }^{19}$. Pero no parece estar tan claro este derecho según se deduce de la resolución de la Sección de Gracia y Justicia del Consejo Real de España e Indias remitida a la. Diputación de Vizcaya en 17 de Octubre de 1834. En esta resolución, derivada de un conflicto entre los vecinos de la Anteiglesia de Vedia y la Diputación de Vizcaya en relación con la presentación de Beneficiados de Galdácano, se declara que «la Real orden de 16 de Marzo de 1808, en cuya virtud ha procedido (se refiere a la presentación de beneficiados hecha por la Diputación), ni por su literal contesto, ni mucho menos por su genuino y claro espíritu, no le concede en manera alguna el derecho de presentar los beneficios dependientes de los Patronatos, cuyos solos productos le han sido cedidos para atender a las necesidades de los espósitos... "20. Al parecer los tiempos van cambiando y en 1834 ya es posible cuestionarse los derechos de presentación de beneficios de quienes disfrutan por merced real de algún patronato, tal como es el caso de la Diputación de Vizcaya, que en virtud de la R. O. De 16 de marzo de 1808 , disfrutaba de los patronatos realengos que hubiesen vacado de sus anteriores poseedores.

\footnotetext{
18 AFB-A, PA, Reg. 1, leg. 3.

AFB-A, PA, Reg. 1, leg. 3.

20 AFB-A, ORGFB, Caja 158
} 


\section{LAS ASPIRACIONES DE LA DIPUTACIÓN DE VIZCAYA POR EL CONTROL DE LOS PATRONATOS: EL ESTABLECIMIENTO DE EXPÓSITOS}

Ya desde 1648 se pueden encontrar intentos por parte del Señorío de hacerse con el control de los patronatos de realengo. En las Juntas Generales reunidas como era costumbre «so el arbol de la antigua de Guernica Dia Miercoles que se quitan seis dias del mes de mayo de mil y seiscientos y quarenta y ocho años», se adoptó el siguiente acuerdo: «Que se suplique a su Magd. que en bacando algunos patronazgos haga merced al Señorío para que mejor pueda acudir a su Real servicio» ${ }^{21}$. De nuevo en la reunión de las Juntas Generales del 7 de mayo de 1653, se solicita para el Señorío el patronazgo de Mallavia. En este caso se recurre a la Ley $6 .^{a}$ del Título $1 .^{\circ}$ del Fuero de Vizcaya, para pedir que no le sea concedido el patronato de Mallavia a Don Pedro Ignacio de Alcolazas e Idiáquez, por no ser natural del Señorío, solicitando para el Señorío la merced del mismo en remuneración de los servicios que continuamente presta a S.M. ${ }^{22}$. En 1612 y en 1704, las Juntas Generales habían solicitado también la concesión de los patronatos mercenarios, es decir de los patronatos realengos, del Señorío para la fundación de una casa de la orden de San Juan ${ }^{23}$.

Finalmente, en 1808, la Diputación de Vizcaya consiguió que el rey Carlos IV, por Real Orden de 16 de marzo de 1808, le concediese dichos patroniatos ${ }^{24}$. El Señorío había conseguido que por R.O. de 2 de Septiembre de 1806, se estableciera una casa de expósitos en la villa de Bilbao, al cuidado y bajo la dirección del propio Señorío, totalmente independiente de la inclusa de Calahorra, ya que los niños del Señorío que eran llevados a dicha casa de Calahorra, perecían en su gran mayoría en el camino. Para el mantenimiento de este Establecimiento de expósitos, se había

\footnotetext{
AFB-A, JGGM, Libro 11, Folio 69v.

22 «Porquanto se havia tenido noticia que su Magd. Ha sido servido de hacer merced a Don Pedro Ignacio de Alcolazas e Idiaquez del Patronazgo y onores de Mallavia... y por no ser el dho... vizcayno no se le pudo hacer del dho Patronazgo= Por tanto acordó su S. ${ }^{\text {a }}$ que se suplique a su Magd. Con toda umildad y beneraciori se sirba de hacerle merced del dho Patronazgo en remineracion de los continuos servicios que le ha hecho y haze asi de marineria... como de Infanteria...". Pero no sólo se hace la súplica, sino que se ordena que «... el señor Corregidor provea autto mandando embargar los dhos frutos para que esten de manifiesto para el que los hubiere de haver, o, sobretodo para quien Su Magd. Fuere servido mandar", dando por hecho que el patronato le sería retirado al mencionado Alcolazas, cosa que al parecer no ocurrió. (AFB-A, JGGM, Libro 11, folio 218r.).

23 AFB-A, JGGM, Libro 6, folio 305, y Libro21, folio 200.
} 
concedido al Señorío el producto del indulto cuadragesimal, uno de los que, junto al indulto de lacticinios, la Bula de Difuntos y la de Composición, integraban la recaudación de la Bula de Cruzada. Al parecer el producto de dicho indulto cuadragesimal era insuficiente para cubrir las necesidades del Establecimiento de expósitos y la Diputación, a través de Don Francisco de Aranguren, Diputado en Corte del Señorío, elevó una solicitud al rey Carlos IV, que fue atendida tal como queda referido.

Como ya se ha visto, esta concesión fue el origen de nuevos conflictos, uno de los cuales fue el motivado por la concesión, el 7 de diciembre de 1814, de los patronatos de Frúniz, Lemóniz, Górliz, Busturia, Albóniga y Basigo de Baquio a Doña Josefa Colón y Sierra. Esta concesión, realizada por Fernando VII, tal como lo expone la Diputación en el memorial remitido a S. M. solicitando la restitución al Establecimiento de expósitos de los mencionados patronatos, fue debida a la influencia del padre de Doña Josefa, Don José Colón de Larreátegui, del Consejo y Cámara del rey, quien logró para ella dichos patronatos, cuyo producto anual era de entre 50 y 60 mil reales ${ }^{25}$, una cantidad nada despreciable si se tiene en cuenta que según el memorial de la Diputación, el gasto diario del mantenimiento de los 483 niños que en aquel momento había en la casa de expósitos, ascendía a 966 reales. Con las rentas de dichos patronatos se podría mantener diariamente a 82 niños.

A partir de 1808, por tanto, todas las vicisitudes por las que pasaron los patronatos reales de Vizcaya y sus concesiones estuvieron directamente relacionadas con la concesión de los mismos a la Diputación de Vizcaya para el mantenimiento del Establecimiento de expósitos. Poco antes de la Real Orden de 16 de marzo de 1808, el 19 de septiembre de 1807, la Cámara había dispuesto la suspensión de la provisión de los patronatos realengos de Vizcaya hasta que sus iglesias estuviesen reparadas y surtidas de todo lo necesario para el culto, lo que indica que probablemente los

24 «Condescendiendo el Rey con la solicitud hecha por Don Francisco de Aranguren y Sobrado Diputado en Corte del Señorío de Vizcaya, ha venido S.M. en conceder al mismo Señorío todos los Patronatos que en él corresponden a la Corona, acabado que sea el tiempo de las gracias o mercedes Reales con destino a la manutención, crianza y educación de los niños expósitos de que se estableció una casa en el propio Señorío a virtud de Real Orden de dos de Septiembre de mil ochocientos y seis; entendiéndose dicha concesión de sólo el sobrante de los expresados Patronatos después de atendidas las Fábricas de sus Iglesias respectivas conforme a la obligación de ellos mismos= Lo traslado a V.S.S. de orden de S.M. para su inteligencia y demás efectos convenientes. Dios guarde a V.S.S. muchos años. Aranjuez diez y seis de Marzo de mil ochocientos y ocho $=$ El Marqués Caballero= Señores de la Junta del Señorío de Vizcaya=" (AFB-A, PA, Reg. 2, leg. 20).

25 AFB-A, PA, Reg. 1, leg. 10. 
patronos no se ocupaban con la suficiente diligencia del mantenimiento de las iglesias. Así pues, en el momento de la concesión de los patronatos a la Diputación, en 1808, pesaba sobre ellos la mencionada orden. Esta suspensión fue confirmada por una Real Orden de 30 de junio de 1814, en la que al mismo tiempo se mandaba que, en atención a que las iglesias debían haber padecido mucho durante la guerra, se tomase conocimiento del estado de ellas y de los patronatos. Esta última orden fue comunicada al Obispo de Calahorra el 13 de marzo de 1815 para que remitiese un informe del estado de las iglesias y patronatos de su diócesis. Nuevamente, el 15 de julio del mismo año la Real Cámara remite un escrito al Obispo de Calahorra solicitándole que «informe cuanto constare y se le ofreciese sobre este asunto, oyendo instructivamente a los interesados de los $\mathrm{Pa}$ tronatos comprendidos en la expresada Real Orden de diez y seis de Marzo, y expresando su estado actual, el de la fábrica material de las Iglesias, ornamentos y vasos sagrados, debiendo practicarse estas diligencias con intervención y audiencia de la Diputación del mismo Señorío de Vizcaya...» ${ }^{26}$. El Obispo de Calahorra, con fecha 24 de julio de 1815, dirigió un escrito a la Diputación de Vizcaya en el que requería de ésta y de los poseedores de Patronatos Realengos de sus Iglesias toda la información que pudiesen aportar con el fin de dar cumplimiento a la Real Orden del 13 de marzo. Esta situación de indefinición, agravada por la concesión ya mencionada de varios patronatos a Doña Josefa de Colón por Real Orden de 7 de diciembre de 1814 y por la gracia de 40.000 reales anuales que, por Real decreto de 11 de diciembre de 1816, concedió Fernando VII al Seminario de nobles de Vergara en frutos de patronatos reales vacantes, dio lugar a una situación enormemente conflictiva. Todo ello, junto con la comisión que en 9 de agosto de 1824, tras el paréntesis que supuso el trienio liberal, se dio por la Cámara a Don Francisco Javier de Aranguren para averiguar los patronatos usurpados a la corona en el Señorío de Vizcaya, parecía poner en tela de juicio la validez de la Real Orden del 16 de marzo de 1808.

Mientras tanto la Diputación intentó conseguir todos los patronatos reales que fueran vacando en el Señorío, pero en muchos casos tuvo que enfrentarse con otros aspirantes a tales mercedes. Tal es el caso del patronato de Rigoitia, que, tras quedar vacante, fue solicitado a S. M. por Don Joaquín María de Ugarte. La Diputación fue consiguiendo así los patronatos de Basauri y Arrigorriaga, en 1825 por fallecimiento de la Marquesa de Mejorada; también en 1825 el de Acorda; en 1931, por muerte

26 AFB-A, PA, Reg. 2, leg. 6. 
de la Marquesa de Rioflorido, los de Galdácano, Echévarri y Mallavia. Durante la época de la Diputación Carlista, en 1938, pasarían a la Diputación todos los patronatos que habían sido de la Condesa de Mora, por fallecimiento de ésta, y que se encontraban secuestrados.

Aunque tal como ha quedado explicado anteriormente no estaba claro si correspondía a la Diputación el derecho de presentación de beneficios en virtud de la Real Orden de 16 de marzo de 1808, ésta, en las tomas de posesión de patronatos que realizaba, hacía siempre referencia a dicho derecho y hacía uso de él, dando lugar a los conflictos ya mencionados. En la toma de posesión por parte del Síndico Procurador General del Señorío, en representación del Establecimiento de expósitos, de los patronatos de Arrigorriaga y Basauri, que habían quedado vacantes por muerte de la Marquesa de Mejorada, se siguió un complejo ritual que venía a demostrar que las aspiraciones de la Diputación iban más allá que la simple recaudación de los diezmos. En el acta que se levantó el día 10 de noviembre de 1824 de la toma de posesión del Patronato de la iglesia de San Miguel de Basauri, se describen estos rituales de la siguiente forma: «... Su Señoría dio a dicho Síndico Procurador General a nombre de dicha Diputación General posesión real actual corporal velquasi ${ }^{27}$ del Patronato de esta Iglesia, y de sus Diezmos, rentas, derecho de presentar Beneficios y demás que le corresponden en virtud de la Real Orden unida a este expediente, $y$ en señal de esta posesión le hizo entrar en la Iglesia y sentarse en la silla y asiento preeminente, le hizo pasar a la Sacristía y poner su mano sobre uno de los cajones en que se custodian los ornamentos y vestiduras sacerdotales del culto divino, abrir y cerrar los cajones y las puertas de la Sacristía y las principales de la Iglesia, y despojar a todas las personas que dentro se hallaban con otros actos y ceremonias de estilo en semejantes casos y conformes a derecho...» ${ }^{28}$.

Sería en 1834 cuando definitivamente quedase consagrado el derecho de la Diputación de Vizcaya a todos los patronatos realengos de la provincia, con destino a la crianza y rnanutención de expósitos. Por una Real resolución del Consejo Real de España e Indias del 6 de diciembre de 1834, comunicada a la Comisión Regia del Señorío de Vizcaya por la sección de Gracia y Justicia del citado Consejo en oficio de 11 del mismo mes, se mandaba que la Real Orden de 16 de marzo de 1808 debería

${ }_{27}$ Según el Diccionario enciclopédico de Derecho usual de Guillermo Cabanellas (Buenos Aires, 1981), la posesión vel cuasi denota aquella que no es tan sólo real y corporal, sino además comprensiva de los derechos y demás bienes inmateriales objeto de la cuasi posesión.

28 AFB-A, PA, Reg. 1, Leg. 13. 
tener cumplido efecto, por lo que correspondía a la Diputación de Vizcaya entrar en el goce y disfrute de los sobrantes de los patronatos de la corona que hubiesen vacado con posterioridad a dicha concesión, «aunque se hayan provisto a favor de particulares o se hayan aplicado al establecimiento del seminario de nobles de Vergara». Se mandaba, así mismo, atender en primer lugar a la reparación de las iglesias, suministrando a las mismas de todo lo necesario para el culto, para lo cual se encomendaba a la misma Diputación y al obispo de Calahorra la tarea de determinar dichas necesidades y la manera de satisfacerlas. Se mandaba también que no se admitiesen memoriales en solicitud de patronatos de Vizcaya bajo ningún pretexto y que éstos no sean concedidos en ningún caso a nadie. Por otra parte, se declaraba por concluida la comisión que la extinguida Cámara había dado en 9 de agosto de 1824 a Don Francisco Javier Aranguren, quien debería entregar toda la documentación en su poder a la propia Diputación, la que como principal interesada por la aplicación de los sobrantes de los patronatos de la corona, cuidaría de indagar los que hubiesen sido usurpados. En el mismo oficio se requería a la Diputación de Vizcaya para que trasladase la citada resolución a Doña Josefa de Colón y a Don Francisco Javier de Aranguren ${ }^{29}$.

Las aspiraciones de la Diputación de Vizcaya habían acabado finalmente con un instrumento con el que había contado la monarquía desde la Edad Media para recompensar los servicios de la nobleza y para comprar su fidelidad. Los patronatos reales, a partir de 1834, irían poco a poco a parar en manos de la Diputación. Queda como un tema abierto para su posterior estudio el del derecho de presentación de beneficios, del que nada se dice, sin embargo, en la citada resolución de diciembre de 1834.

Según se deduce de la mencionada resolución del Consejo Real, los patronatos de Frúniz, Lemóniz, Górliz, Busturia, Albóniga y Baquio, que habían sido concedidos a Doña Josefa de Colón habrían debido pasar inmediatamente a la Diputación de Vizcaya. Sin embargo, entre la documentación de la Diputación Carlista, con sede en Durango desde julio de 1836, pero que había sido constituida ya en 1834, se encuentra un escrito dirigido a S.M. Carlos $5 .^{\circ}$, sin fecha, pero, sin duda alguna, posterior a 1834, en el que se solicita del mismo ordene secuestrar aquellos" «Patronatos Mercenarios o de gracia Real que gozan personas desleales a la causa justa del Sr. Dn. Carlos $5 .^{\circ}{ }^{30}$, en el que aparecen los patronatos de dichos pueblos como pertenecientes al Conde de Espeleta. En el Anexo III se ha incluído una re-

29 AFB-A, ORGFB, Caja 158.

30 AFB-A, PA, Reg. 2, leg. 14. 
lación de los patronatos que en 1834 se encontraban en manos de la Diputación de Vizcaya con destino al Establecimiento de expósitos.

\section{LAS PESQUISAS SOBRE PATRONATOS}

Con diferentes objetivos, se realizaron durante los siglos XVIII y XIX varias pesquisas tendentes a obtener información de los patronatos de Vizcaya. En unos casos se trataba de conocer el estado de las iglesias a fin de ocuparse de su reparación, en otros el objetivo era conocer la situación de los patronatos realengos con el fin de conceder aquéllos que estuviesen vacantes. Otro objetivo podía ser el conocer el valor anual de sus frutos con el fin de establecer una contribución extraordinaria sobre los mismos, o incluso para averiguar los títulos que poseían los patronos con el fin de resolver los pleitos pendientes sobre los mismos.

Se realizó una pesquisa de patronatos en 1416 como consecuencia de la cual existe en el archivo de Simancas una relación de patronatos realengos y diviseros de las iglesias de Vizcaya. Este documento fue trasladado literalmente en 1708 y posteriormente en $1774^{31}$. Otra pesquisa fue ordenada en 1718 por la que se requería «a todos los Patronos propietarios, Administradores, llevadores de Diezmos, arrendatarios y demás personas y comunidades de cualquiera estado grado y calidad... remitan testimonio de todos los Patronatos y llevadores de Diezmos que hubiese en cada uno de los lugares de su territorio sin reservación de alguno de ellos..." ${ }^{32}$. El objetivo era recoger toda la información necesaria para proceder al embargo de los mismos para el cobro del valimiento, según las. Reales Órdenes de 16 de febrero de 1718 y 14 de marzo del mismo año.

Por Orden de 31 de agosto de 1767, la Cámara requirió a todos los patronos de Vizcaya para que presentasen todos los privilegios, títulos y demás documentos que poseyesen a fin de conocer detalladamente el valor anual de cada uno de los Patronatos Realengos que había en el Señorío, qué cargas tenían y del estado en que se hallaban las fábricas de sus respectivas iglesias. Consecuencia de esta pesquisa fue el pleito del que ya se ha hablado entre la villa y el Cabildo eclesiástico de Bilbao. El 13 de octubre de 1783 se comunicó al Corregidor Don Juan Felipe López de Mena la Real Cédula que ordenaba la averiguación del valor anual de los Patronatos Realengos y el estado en que se hallaban las Fábricas, mandando que

31 AFB-A, PA, Reg, 1, leg. 11.

32 AFB-A, PA, Reg. 1, leg. 11. 
practicase las diligencias conducentes a descubrir los Patronatos usurpados a la corona. El 28 de marzo de 1800 la Suprema Cámara comisionó al Corregidor del Señorío, Don Luis Marcelino Pereira, para que continuase el expediente comenzado por su antecesor, Don Juan Felipe López de Mena.

El 20 de abril de 1807, una Real Orden relativa a los Planes Beneficiales solicitaba una información detallada de las parroquias del Señorío. Algunos pueblos enviaron una información detallada que se adjuntó a los expedientes formados como consecuencia de la orden de Thouvenot de 1810.

Contrasta con la lentitud de los trámites anteriores el gran esmero con que fue realizada la pesquisa ordenada en 2 de agosto de 1810 por el General Thouvenot para «que los Consejos Municipales y Cabildos Eclesiásticos remitan en el término de ocho días todos los papeles que hubiese en sus archivos relativos a los Patronatos de su distrito expresando si las Iglesias son de Patronato, quienes son sus poseedores y cuales los derechos que gozan " ${ }^{33}$. Como resultado de los informes enviados por los Consejos Municipales y por los Cabildos existe una buena colección de expedientes de los que se ha obtenido información de gran valor para este estudio. El extraordinario celo de algunos Consejos Municipales llevó, por ejemplo, al de Ondárroa a enviar el original de un privilegio dado por los Reyes Católicos, que se encuentra archivado junto con su expediente.

En 1824, tal como queda dicho, fue comisionado Don Francisco Javier de Aranguren por Real Carta Orden de 19 de agosto para que continuase las averiguaciones iniciadas en 1783 por Don Juan Felipe López de Mena. En escrito del 7 de septiembre de 1833 la Diputación solicita al Sr. Aranguren toda la información de que disponga sobre el asunto. En respuesta de éste del $16 \mathrm{del}$ mismo mes, tras exponer los antecedentes de la misión que le fue encomendada en 1824, manifiesta las dificultades de todo tipo que encontró para obtener la información requerida ${ }^{34}$.

\section{CONTRIBUCIONES EXTRAORDINARIAS}

Ya se ha hecho referencia al embargo para el valimiento ${ }^{35}$ ordenado por las Reales Órdenes de 16 de febrero de 1718 y 14 de marzo de 1718.

33 AFB-A, ORGFB, Caja 168.

34 AFB-A, PA, Reg. 2, leg. 21.

35 Según el Diccionario Enciclopédico Espasa, el valimiento es un servicio transitorio que el rey mandaba le hiciesen sus súbditos de una parte de sus bienes o rentas para alguna urgencia. 
Desde entonces no se había vuelto a recurrir a las rentas de los patronos directamente con el fin de obtener fondos para la Hacienda Real, aunque se hubiera hecho de forma indirecta mediante las contribuciones propias del clero, como el subsidio de treinta millones de reales concedido el 16 de abril de 1817 por Pio VII, reducido a 10 millones en 1823, y del cual fueron excluidos los perceptores laicos de Cataluña, por el Breve papal de León XII, de fecha 4 de diciembre de $1827^{36}$.

Fue bajo el gobierno de Thouvenot cuando se impuso una contribución de 6.500 .000 reales a las tres provincias de Vizcaya, Guipúzcoa y Álava, mediante el Decreto del 13 de marzo de 1810. Ante las dificultades para realizar el reparto de la misma, en sesión del Consejo de Provincia del 22 de junio se realizó el reparto de un millón de reales entre los pueblos del Señorío, el comercio y el clero. En este reparto, a los pueblos del Señorío, es decir, lo que podría considerarse como una contribución territorial, les correspondieron 657.783 reales, al comercio y a los capitalistas de la villa de Bilbao, 234.412 reales y al clero de la provincia, 108.191 reales. En la contribución correspondiente al clero se computaban tres conceptos: el primero, sobre Patronos llevadores de diezmos, el segundo, sobre Beneficios y curatos y el tercero sobre capellanías.

\section{Cuadro I}

Contribución de 1810

\begin{tabular}{lcc}
\hline \multicolumn{1}{c}{ Concepto } & Reales Vn. & $\%$ \\
\hline Los pueblos del Señorío & 657.783 & $65^{\prime} 8$ \\
El comercio y los capitalistas de Bilbao & 234.412 & $23^{\prime} 4$ \\
Los Patronos llevadores de diezmos & 39.962 & 4 \\
Los Beneficios y curatos & 58.593 & 5 '8 \\
Las capellanías & 9.614 & 1 \\
Total & 1.000 .364 & 100 \\
\hline
\end{tabular}

En Circular del 4 de febrero de 1834, la Diputación General del Señorío «... para cumplir con las perentorias obligaciones que pesan sobre ella necesitará a los menos 200.000 reales mensuales... ha acordado excitar el celo de la comisión general de subsistencias, a fin de que proponga algún

${ }^{36}$ Real Cédula de S.M. y Señores del Consejo, del 31 de marzo de 1828, reimpresa en Bilbao por Eusebio de Larumbe. (BDFB, VF-2447). 
medio de reunir la enunciada cantidad, valiéndose de las clases esceptuadas por su carácter privilegiado...” ${ }^{37}$. El día 18 del mismo mes, la Junta de Subsistencias realizó una propuesta según la cual se llevaba a cabo un reparto inspirado en la contribución de Thouvenot, pero cuyos porcentajes variaban sustancialmente, siendo el clero el que resultaba más gravado, con un $40 \%$ del total de la contribución que se esperaba recaudar. A los patronos se les imponía un $4 \%$ de los rendimientos líquidos de los frutos que percibiesen, aunque se esperaba que este porcentaje ascendiese a los 20.000 reales necesarios para completar la recaudación de 200.000 . Con el fin de conocer el importe de los rendimientos de los patronatos de la provincia se elaboró una estadística del líquido de diezmos. En la reunión del 13 de marzo, a la que habían sido convocados los patronos laicos de la provincia, se nombró la Comisión de Patronos encargada de la elaboración de dicha estadística. Esta comisión estaba integrada por los señores Don Juan José de Mugartegui, Don " ngel Martínez (administrador de la Condesa de Mora), Don Celestino - Mazarredo, Don Gregorio de Lezama-Leguizamón y Don Víctor de Munive ${ }^{38}$.

Cuadro II

Contribución de 1834 (mensual)

\begin{tabular}{lcc}
\hline \multicolumn{1}{c}{ Concepto } & Reales Vn. & $\%$ \\
\hline Comerciantes y capitalistas de la provincia & 33.000 & 16 '5 \\
Comerciantes y capitalistas de Bilbao & 67.000 & 3,5 \\
Los Patronos llevadores de diezmos & 20.000 & 10 \\
El Clero & 80.000 & 40 \\
Total & 200.000 & 100 \\
\hline
\end{tabular}

La Comisión de Patronos realizó un minucioso trabajo, formando una estadística bastante completa de los rendimientos de todos los patronatos de Vizcaya, excluyendo aquellos que pertenecían a la Diputación para el establecimiento de expósitos. Hay que tener en cuenta que lo más probable es que los cálculos de los rendimientos se hicieran a la baja, ya que no se había establecido por la Junta de Subsistencias una cantidad fija con la que deberían contribuir, sino un porcentaje (el $4 \%$ ) de los rendimientos.

37 AFB-A, CC, Reg. 15, leg. 5.

38 AFB-A, CC, Reg. 15, leg. 5, folios 83-84. 
Los rendimientos de los patronatos tal como fueron calculados por esta comisión son los que quedan reflejados en el Anexo II.

En 1836, la Diputación Carlista, en virtud de la Real Orden de 31 de julio de 1836, procedió al embargo o secuestro de los bienes pertenecientes a personas ausentes de la provincia o comprometidas en «la usurpación revolucionaria». Entre estos bienes se encontraban también las rentas procedentes de patronatos. En el Anexo / figuran los rendimientos de patronatos laicos obtenidos durante el año 1837 por la Diputación Carlista como consecuencia de estos embargos. Con el fin de realizar la recaudación de los diezmos de los patronatos secuestrados, el 24 de agosto de 1836, la Diputación dirigió una Circular a los Cabildos de la provincia pidiéndoles su colaboración en la recolección de todos los diezmos que perteneciesen a Patronatos de las personas comprendidas en la Real orden de 31 de julio ${ }^{39}$.

\section{¿LOS PATRONATOS DE LAICOS EN PELIGRO?}

Los años del trienio liberal parecieron el anuncio de algo que finalmente no llegaría. Todo parecía que iba a cambiar. Era tan grande el entusiasmo que se ponía y tan fuertes las resistencias que ninguno de los proyectos terminaría por ponerse en marcha. Además hubo tan poco tiempo para hacerlo, que cuando se quiso empezar ya se había terminado todo. Una vez pasado, todo quedó convertido en un sueño para algunos y en una pesadilla para otros. La Diputación de Vizcaya, compuesta por liberales y constitucionalistas convencidos trató de acabar con los Patronatos en la primera ocasión que tuvo, aunque, probablemente, con el entusiasmo de los primeros momentos no llegaron a darse cuenta de los intereses económicos y de todo tipo que estaban en juego.

La Diputación Provincial de Vizcaya en su reunión del 5 de junio de 1820 , visto el Decreto de las Cortes de 13 de abril, en el que se ordena llevar a efecto el del 6 de agosto de 1811 por el que se incorporaban a la Nación los Señoríos jurisdiccionales y quedaban los territoriales como propiedades particulares, elaboró un decreto, con cuatro artículos, por el que

\footnotetext{
39 «Estando cometida a esta Diputación general la administración de los bienes pertenecientes a las personas comprendidas en la Real orden de 31 de Julio último... ha fijado su atención en que ninguno como los respetables Cabildos pueden desempeñar este delicado e importante encargo... de principio inmediatamente a la recolección de todos los diezmos que pertenezcan a Patronatos de las personas comprendidas...» (AFB-A, DG, Reg. 13 bis, leg. 2).
} 
se declaraban suprimidos para siempre en la provincia de Vizcaya los derechos señoriales, entre los que se citaban los que se exigían por lanzas mareantes y vallesteros, los maravedís, los derechos de prebostada y el albalá del fierro. En cuanto a los Patronatos señoriales de la provincia se reservaban el acordar en otra sesión lo conveniente al respecto ${ }^{40}$. En la sesión del día siguiente, 6 de junio, se redactó un decreto con cinco artículos, que posteriormente quedaron convertidos en cuatro, ya que el primero de ellos aparece tachado en el acta original. La Diputación pretendía suprimir todos los Patronatos, declarándolos de propiedad particular de la provincia y destinándolos a la subsistencia de los expósitos y a otros fines que redundasen en beneficio de la provincia: « $4 .^{\circ}$. Se remitirá por mano del Sr. Presidente copia certificada de este decreto al gobierno superior con la representación conveniente apoyada por S.S. a fin de que se digne aprobarle y disponer que los rendimientos de dichos Patronatos declarados por propiedad particular de la Provincia se destinen a la subsistencia de los expósitos y otros fines que redunden en beneficio de aquella en caso de haber sobrante llevando razón y cuenta circunstanciada» ${ }^{41}$.

La supresión de los derechos señoriales, al parecer, no era sólo una aspiración de los liberales, ya que tras conocerse el decreto de supresión de los derechos señoriales, los curas párrocos de la villa de Portugalete solicitaron que se devolvieran a sus iglesias los diezmos con que anteriormente se contribuía a la dotación del Señor de Vizcaya. A consecuencia de esta solicitud, la Secretaría de Gracia y Justicia comunicó a la Diputación con fecha 17 de agosto de 1820 una Real Orden para que informara sobre tal petición. En una representación del 13 de octubre, la Diputación expone sus criterios en relación con tal asunto. De ellos se deduce que la Diputación juzgaba que los patronatos reales no deberían subsistir porque tenían el concepto de unos derechos señoriales suprimidos por el decreto del 6 de agosto de 1811, pero «Ocurrió sin embargo la duda a la Diputación de si los derechos suprimidos debian de quedar en beneficio de los primeros contribuyentes o de toda la Provincia que sería la que regularmente acordara los impuestos y derechos asignados al Señor... Pero jamás le ocurrió que los curas pudieran ser de mejor derecho para percepción de unos frutos que nunca les han correspondido. En norabuena que ellos tengan una acción a que se les dote convenientemente según las funciones que exercen en la sociedad, pero deben atenerse a los medios que la Nación adopte para ello...» ${ }^{42}$. La Diputación considera

40 AFB-A, ORGFB, Caja 165, leg. 1.

AFB-A, ORGFB, Caja 165, leg. 5.

2 AFB-A, ORGFB, Caja 165, leg. 2. 
los diezmos como una contribución secular que, por lo tanto, no tiene sentido que sea recaudada por la Iglesia. Esta tiene derecho a que se le dote convenientemente para poder cumplir con la función que tiene asignada en la sociedad, pero en ningún caso debería poder convertirse en recaudadora de contribuciones. La Diputación cree que los Patronatos Reales, dado que se trata de una institución señorial, deberían cesar totalmente, pero no así los diezmos, "porque en su defecto se grabaría la Provincia con diferentes pedidos de los que pagan otras, y cuando su producto no se tenga por conveniente aplicar a los expósitos, deben quedar en beneficio de los primeros contribuyentes y no del clero, quien nada más podrá pedir sino que se le aumente la dotación, cuando fuere corta, hasta la cantidad suficiente». Se aprecia en estas opiniones que el punto de vista defendido por la Diputación se aproxima al de los diputados de las Cortes generales que unos meses más tarde aprobarían los Decretos LXVII y LXVIII del 29 de junio de 1821 sobre reducción de diezmos y primicias. En estos mismos decretos se regulaban las indemnizaciones a los partícipes laicos de diezmos.

Fruto de estos decretos de junio de 1821 es el de 29 de enero de 1822 por el que se ordena crear en todas las diócesis una Junta de partícipes seculares de diezmos encargadas de llevar a cabo el reintegro y la indemnización de los partícipes legos y de vigilar que no se rebajen fraudulentamente los valores del medio diezmo destinado a la dotación del culto $y$ del Clero ${ }^{43}$. Resulta poco menos que curioso el cambio en la terminología, ya no hay Patronos, sino simples partícipes legos.

El sueño, o la pesadilla, terminó enseguida y el 6 de junio de 1823 se publicaba la Orden circular expedida por el Ministerio de Hacienda, por la que se anulaba el decreto de las Cortes de 29 de Junio de 1821 relativo a diezmos ${ }^{44}$. Parecía que todo volvía a ser como antes.

Los Patronos volvieron a disfrutar plenamente de todas sus prerrogativas y derechos. El 20 de mayo de 1824, el Patrono de Lujua, Don Francisco Xavier de Vatiz, en representación de varios patronos, dirigió un escrito a la Diputación suplicando su intervención con el fin de dar solución al agravio que sufrían éstos en el derecho que poseían de presentación de

43 Circular de la Diputación de Vizcaya a los Ayuntamientos, de fecha 16 de Marzo de 1822. (BDFB, VAF-15).

44 Esta Orden comenzaba así: «La indiscreta pasión por la novedad, y el criminal empeño de engañar a los pueblos con falaces y seductoras teorías hizo que el Gobierno revolucionario en 29 de Junio de 1821 redujese a la mitad las cuotas que se pagaban por razón de diezmos y primicias..." (Colección de Leyes y Decretos, Tomo 7 BDFB, B-817). 
Beneficios, por cuanto el último Plan Beneficial requería indispensablemente la edad de veintitrés años en cualquiera que hubiese de ser presentado. Según los patronos esta limitación les hacía verse privados de la prerrogativa de presentación de Beneficios ${ }^{45}$.

Pasados los momentos difíciles de la guerra civil en los que la provincia estuvo dividida y durante los cuales hubo dos Diputaciones y dos sistemas políticos enfrentados en el campo de batalla, todo volvía a una normalidad nueva, siguiendo la cita literaria que se ha convertido en un tópico, todo había cambiado para que nada cambiase. Sin embargo, sí que habían cambiado muchas cosas. En una Circular del 21 de Diciembre de 1839, la Diputación de Vizcaya vuelve a invocar la Ley $6 .^{a}$ Título $1 .^{\circ}$ de los Fueros en que se ordena que los diezmos de Vizcaya no se apliquen a quien no sea natural del Señorío, para encargar «a todas las justicias de este Señorío que procuren por ahora y mientras se halle pendiente el insinuado arreglo (se refiere al prometido en la ley de 25 de Octubre de 1839), no consentir innovaciones de ninguna clase, ni en la cobranza y distribución de diezmos..." ${ }^{46}$.

A pesar de todos los pasos hacia delante que se habían ido dando durante los últimos años, se puede apreciar la vitalidad de la mentalidad aristocrática que defiende unos privilegios estamentales con tanta más fuerza e intensidad cuanto mayor es la amenaza que se cierne sobre ellos. En Julio de 1844, varios patronos diviseros se dirigen a la Diputación de Vizcaya mediante un escrito en el que se hace referencia al Real Decreto del 4 de julio que restablecía el sistema foral, salvas las excepciones que especificaba, y en el que se expone la situación en la que, habiendo sido suprimidos los diezmos, se atenta contra las leyes $1 .^{a}$ y $2 .^{\text {a }}$ del título 32 del Fuero de Vizcaya, en las que se reconoce la existencia de los monasterios o patronatos de su Alteza y de los diviseros. Reclaman el respeto al código foral y solicitan que se vuelva a restablecer el pago de los diezmos. Para ello invocan tanto al Fuero de Vizcaya, que protege a los patronos de sus iglesias, como al «sagrado derecho de propiedad" y a la religiosidad del pueblo vizcaino. Su objetivo es «convencer que es de toda justicia el que se ordene el pago de los diezmos a los respectivos patronos", y entre las razones que aducen es significativa la de que los sobrantes de los diezmos sirven «para el decoro y lustre de casas principales del país y de personajes oriundos de él que los poseen desde siglos remotos" ${ }^{47}$.

AFB-A, PA, Reg. 2, leg. 12 ,

AFB-A, ORGFB, Caja 158.

AFB-A, PA, Reg. 2, leg. 19. 
NOTAS

* Se han utilizado las siguientes abreviaturas:

$\begin{array}{ll}\text { AFB } & \text { Archivo Foral de Bizkaia. } \\ \text { A } & \text { Administrativo. } \\ \text { BSE } & \text { Bienes Secuestrados y Embargados. } \\ \text { CB } & \text { Congruas Beneficiales. } \\ \text { CC } & \text { Culto y Clero. } \\ \text { CO } & \text { Contribuciones. } \\ \text { DG } & \text { Diputación General. } \\ \text { JGGM } & \text { Juntas Generales de Guernica (Manuscritas). } \\ \text { LH } & \text { Libros Históricos. } \\ \text { OCD } & \text { Órdenes y Circulares de la Diputación. } \\ \text { ORGFB } & \text { Órganos y Régimen de Gobierno. Fondo Balparda. } \\ \text { PA } & \text { Patronatos. } \\ \text { BDFB } & \text { Biblioteca de la Diputación Foral de Bizkaia. } \\ \text { DSC } & \text { Diario de Sesiones de las Cortes. }\end{array}$

\section{ANEXO I \\ IGLESIAS DE PATRONATO EN VIZCAYA A COMIENZOS DEL SIGLO XIX}

Relación de Anteiglesias del Señorío de Vizcaya con sus patronatos

Los titulares de los patronatos se han obtenido de los expedientes formados en 1810 como consecuencia de la Orden del Gobernador de Vizcaya, General Thouvenot, del 2 de agosto de 1810, por la que se requería a los Consejos Municipales y a los Cabildos de las iglesias de Vizcaya el envío de informes sobre la situación de los patronatos, sus poseedores y los títulos de los mismos (AFB-A,ORGFB, Caja 168). Los rendimientos mensuales que figuran en la tabla se han obtenido a partir del reparto del $4 \%$ sobre la mitad del líquido producto de los diezmos de los patronos de Vizcaya realizado por la Comisión de Patronos formada a instancias de la Diputación con el fin de recaudar una contribución extraordinaria impuesta a los patronos de Vizcaya. También se han obtenido algunos de los nombres de los titulares, que han variado con respecto a la información de los expedientes de 1810 (AFB-A, CC, Reg. 15, leg. 5). Los rendimientos de 1837 son los obtenidos por el embargo realizado por la Diputación carlista (AFB-A, PA, Reg. 2, leg. 14). 


\begin{tabular}{|c|c|c|c|c|}
\hline Iglesia & $\begin{array}{l}\text { Clase de } \\
\text { Patronato }\end{array}$ & $\begin{array}{l}\text { Prod. mens. } \\
1834\end{array}$ & $\begin{array}{l}\text { Rend. } \\
1837\end{array}$ & Razón de Patronatos (1810) \\
\hline Abadiano & & 5709 & 27040 & $\begin{array}{l}\text { Condesa de Mora (presenta } \\
\text { Beneficios) }\end{array}$ \\
\hline Abadiano & & & & $\begin{array}{l}\text { Marqués de Mortara (lleva } \\
\text { diezmos) }\end{array}$ \\
\hline Abando & & 1650 & & $\begin{array}{l}\text { Mariano Ordóñez de Barrai- } \\
\text { cúa Marqués de Villarias (lleva } \\
\text { diezmos) }\end{array}$ \\
\hline Abando & & & & $\begin{array}{l}\text { Valdecarzana (presenta Bene- } \\
\text { ficios) }\end{array}$ \\
\hline Ajánguiz & & & & Cavildo de Guernica \\
\hline Ajánguiz & & & & $\begin{array}{l}\text { Conde de Montefuerte (José } \\
\text { M. De Allende) }\end{array}$ \\
\hline Ajánguiz & & & & Conde de Peñaflorida \\
\hline Ajánguiz & & & & Condesa de Montijo \\
\hline Ajánguiz & & 4000 & & El Mayordomo de la Fábrica \\
\hline Albóniga & & & 468 & \\
\hline Alonsotegui & & & & $\begin{array}{l}\text { El Beneficiado (percibe los po- } \\
\text { cos frutos) }\end{array}$ \\
\hline Alonsotegui & & & & $\begin{array}{l}\text { Marquesa de Mejorada (pre- } \\
\text { senta el único Beneficio) }\end{array}$ \\
\hline Amorebieta & REALENGO & & & $\begin{array}{l}\text { La Fábrica (percibe los diez- } \\
\text { mos por priv.De Juan II) }\end{array}$ \\
\hline Amorebieta & REALENGO & 3850 & & Los Cabildos \\
\hline Amoroto & & & & $\begin{array}{l}\text { Antonio Adán de Yarza (pre- } \\
\text { voste) }(1 / 3)\end{array}$ \\
\hline Amoroto & & & & El Cabildo (1/3) \\
\hline Amoroto & & & & La Fábrica (1/3) \\
\hline Apatamonasterio & & & 0 & \\
\hline Aracaldo & $\begin{array}{l}\text { Pleito en } \\
\text { la Cámara }\end{array}$ & & & $\begin{array}{l}\text { Valdecarzana (sólo presenta } \\
\text { Beneficios) }\end{array}$ \\
\hline Aránzazu & REALENGO & 200 & 3456 & Condesa de Mora \\
\hline Arbácegui & & 1080 & 4000 & Eulogio de Larrinaga \\
\hline Arcentales & $\begin{array}{l}\text { Pleito en } \\
\text { la Cámara }\end{array}$ & 3083 & 990 & Conde de Miranda \\
\hline Arcentales & $\begin{array}{l}\text { Pleito en } \\
\text { la Cámara }\end{array}$ & 665 & & Joaquin Hurtado de Mendoza \\
\hline Arrancudiaga & $\begin{array}{l}\text { Pleito en } \\
\text { la Cámara }\end{array}$ & 1100 & 2640 & Condesa de Mora \\
\hline Arrazua & DIVISERO & 2200 & 8856 & Conde de Montijo \\
\hline Arrazua & DIVISERO & & & Antonio Adán de Yarza \\
\hline Arrieta & DIVISERO & & & Alejandro de Eguia \\
\hline Arrieta & DIVISERO & 160 & & Condesa de Mora \\
\hline
\end{tabular}




\begin{tabular}{|c|c|c|c|c|}
\hline Iglesia & $\begin{array}{l}\text { Clase de } \\
\text { Patronato }\end{array}$ & $\begin{array}{l}\text { Prod. mens. } \\
1834\end{array}$ & $\begin{array}{l}\text { Rend. } \\
1837\end{array}$ & Razón de Patronatos (1810) \\
\hline Arrieta & DIVISERO & & & Echauz \\
\hline Arrieta & DIVISERO & & & M. ${ }^{\text {a }}$ Manuela de Uria Nafarrondo \\
\hline Arrieta & DIVISERO & & & Manuel Antonio de Zobaran \\
\hline Arrieta & DIVISERO & & & Manuel de Monasterio \\
\hline Arrieta & DIVISERO & & & Manuel M. ${ }^{a}$ de Urdabai \\
\hline Arrieta & DIVISERO & & & Ramona de Arriaga \\
\hline Arrieta & DIVISERO & & & Tomás Ramón de Garai \\
\hline Arrieta & DIVISERO & & & Valmediano \\
\hline Arrieta & DIVISERO & 400 & & Pedro de Meñaca Batiz \\
\hline Arrieta & DIVISERO & 1600 & 3133 & Viuda de Lope de Mazarredo \\
\hline Arrigorriaga & REALENGO & & & $\begin{array}{l}\text { Marquesa de Ynojares y Mejo- } \\
\text { rada }\end{array}$ \\
\hline Arteaga & DIVISERO & 3115 & 10200 & Conde de Montijo \\
\hline Axpe de Arrazola & DIVISERO & & & $\begin{array}{l}\text { Condesa de Mora (lleva parte } \\
\text { de diezmos) }\end{array}$ \\
\hline Axpe de Arrázola & DIVISERO & 1500 & 8184 & Iñigo Melchor Ortesde Velasco \\
\hline Axpe de Busturia & REALENGO & 3239 & 3780 & Conde de Camarena \\
\hline Axpe de Busturia & REALENGO & 178 & & José Antonio de Echevarría \\
\hline Balmaseda & REALENGO & & & El Cabildo (lleva los diezmos) \\
\hline Balmaseda & REALENGO & & & La Villa \\
\hline Baracaldo & divisero & 550 & & $\begin{array}{l}\text { Conde de Corres (presenta } \\
\text { Beneficios) }\end{array}$ \\
\hline Baracaldo & divisero & 550 & & Francisco Domingo de Chabarri \\
\hline Baracaldo & divisero & 550 & & Viuda de Lope de Mazarredo \\
\hline Baracaldo & divisero & 550 & & $\begin{array}{l}\text { Mariano de Castaños (presen- } \\
\text { ta Beneficios) }\end{array}$ \\
\hline Baracaldo & divisero & 550 & & $\begin{array}{l}\text { Saturnino Salazar (presenta } \\
\text { Beneficios) }\end{array}$ \\
\hline Baracaldo & divisero & 550 & & Marqués de Valmediano \\
\hline Barrica & REALENGO & & & $\begin{array}{l}\text { Condesa de Mora (presenta } \\
\text { Beneficios) }\end{array}$ \\
\hline Barrica & REALENGO & & & $\begin{array}{l}\text { Marqués de Valmediano (lleva } \\
\text { los diezmos) }\end{array}$ \\
\hline Basauri & REALENGO & & & $\begin{array}{l}\text { Marquesa de Mejorada (lleva } \\
\text { los diezmos) }\end{array}$ \\
\hline Basauri & REALENGO & & & $\begin{array}{l}\text { Pleito en la Cámara (presenta- } \\
\text { ción de Beneficios) }\end{array}$ \\
\hline Basigo de Baquio & REALENGO & & 2016 & Conde de Camarena \\
\hline Basigo de Baquio & REALENGO & & & La Villa \\
\hline Bedarona & & & & $\begin{array}{l}\text { Antonio Adán de Yarza (11 } \\
\text { casas) }\end{array}$ \\
\hline Bedarona & & & & $\begin{array}{l}\text { El Cabildo de Lequeitio (22 } \\
\text { casas) }\end{array}$ \\
\hline
\end{tabular}




\begin{tabular}{|c|c|c|c|c|}
\hline Iglesia & $\begin{array}{l}\text { Clase de } \\
\text { Patronato }\end{array}$ & $\begin{array}{l}\text { Prod. mens. } \\
\qquad 1834\end{array}$ & $\begin{array}{l}\text { Rend. } \\
1837\end{array}$ & Razón de Patronatos (1810) \\
\hline Begoña & REALENGO & & & $\begin{array}{l}\text { El Cabildo (lleva diezmos y } \\
\text { presenta Beneficios) }\end{array}$ \\
\hline Begoña & REALENGO & 2170 & & $\begin{array}{l}\text { Marqués de Bargas (lleva par- } \\
\text { tede diezmos) }\end{array}$ \\
\hline Berango & DIVISERO & 500 & 350 & Condesa de Mora \\
\hline Berango & DIVISERO & & & $\begin{array}{l}\text { Ventura Gomez (una parte de } \\
\text { diezmos) }\end{array}$ \\
\hline Bermeo & & & & El Cabildo \\
\hline $\begin{array}{c}\text { Bermeo casa } \\
\text { de Trivis }\end{array}$ & & 75 & & Viuda de Lope de Mazarredo \\
\hline Berriatúa & divisero & & 0 & Conde de Peñaflorida \\
\hline Berriatúa & divisero & & & $\begin{array}{l}\text { El Cabildo (lleva parte de diez- } \\
\text { mos) }\end{array}$ \\
\hline Bilbao & REALENGO & & & $\begin{array}{l}\text { El Cabildo (percibe diezmos y } \\
\text { presenta Beneficios) }\end{array}$ \\
\hline Bilbao & REALENGO & & & $\begin{array}{l}\text { La Villa (no percibe diezmos ni } \\
\text { presenta Beneficios) }\end{array}$ \\
\hline Bolivar & DIVISERO & & & La Colegiata de Cenarruza \\
\hline Carranza & & 560 & & Conde de Villafuente \\
\hline Carranza & & 560 & & Alvarado y Cevallo \\
\hline Carranza & & 560 & & Felipe de Trevilla \\
\hline Carranza & & & 750 & Abad de Bibanco \\
\hline Carrariza & & & & casa de Puente Hurtado \\
\hline Carranza & & & & Conde de Noblejas \\
\hline Carranza & & 560 & & Viuda de Lope de Mazarredo \\
\hline Carranza & & 560 & & Romarate \\
\hline Carranza & & & 1500 & El cura \\
\hline Carranza & & & & Benedictinos de Oña \\
\hline Castillo y Elejaveitiz & a DIVISERO & 731 & 1728 & Lucas de Urrecha \\
\hline Castillo y Elejaveitic & a DIVISERO & & & Antonio María de Arriaga \\
\hline Castillo y Elejaveitia & a DIVISERO & 459 & & Ignacio $M{ }^{\text {a }}$ Sanchez de Vicuña \\
\hline Ceánuri & REALENGO & 5690 & 25000 & Diego de Arriola \\
\hline Ceánuri & REALENGO & 187 & & Melquiades María de Goya \\
\hline Ceberio & REALENGO & 4582 & & $\begin{array}{l}\text { «vecinos de la parcialidad» } \\
\text { «Patrona del Valle» }\end{array}$ \\
\hline Ceberio & REALENGO & & & $\begin{array}{l}\text { Villa de Miravalles (lleva diez- } \\
\text { mos y presenta Benef.) }\end{array}$ \\
\hline Cenarruza & DIVISERO & & 11040 & La Colegiata \\
\hline Cortezubi & DIVISERO & 3604 & & Condesa de Cancelada \\
\hline Cuatro concejos & REALENGO & & 5322 & Conde de Miranda \\
\hline Cuatro concejos & REALENGO & & & $\begin{array}{l}\text { Josefa Zid viuda de Don Josef } \\
\text { de Aranguren }\end{array}$ \\
\hline
\end{tabular}




\begin{tabular}{|c|c|c|c|c|}
\hline Iglesia & $\begin{array}{l}\text { Clase de } \\
\text { Patronato }\end{array}$ & $\begin{array}{l}\text { Prod. mens. } \\
\quad 1834\end{array}$ & $\begin{array}{l}\text { Rend. } \\
1837\end{array}$ & Razón de Patronatos (1810) \\
\hline Cuatro concejos & REALENGO & 4517 & & Viuda de Lope de Mazarredo \\
\hline Cuatro concejos & REALENGO & & & Juan José de Escoiquiz \\
\hline Derio & REALENGO & & & Luis de Viguri \\
\hline Deusto & DIVISERO & & & $\begin{array}{l}\text { El Cabildo (por cesión de la } \\
\text { casa Butróny Mújica) }\end{array}$ \\
\hline Deusto & DIVISERO & & & $\begin{array}{l}\text { El Cabildo y el pueblo alternati- } \\
\text { vamente presentanB. }\end{array}$ \\
\hline Dima & REALENGO & 4435 & 12540 & Marqués de Llano \\
\hline Durango & DIVISERO & & & $\begin{array}{l}\text { El Cabildo (lleva diezmos y } \\
\text { presenta Beneficios) }\end{array}$ \\
\hline Durango & DIVISERO & & & $\begin{array}{l}\text { La Villa (no percibe diezmos ni } \\
\text { presenta Beneficios) }\end{array}$ \\
\hline $\mathrm{Ea}$ & & & 0 & Conde de Montijo \\
\hline Echano & & 825 & 3333 & Conde de Montijo \\
\hline Elorrio & REALENGO & & 4000 & $\begin{array}{l}\text { Marqués de Montehermoso } \\
\text { (por dos vidas) }\end{array}$ \\
\hline Erandio & DIVISERO & 6400 & 3000 & Condesa de Mora \\
\hline Ereño & & 3413 & 6480 & Antonio Adán de Yarza \\
\hline Ermua & REALENGO & & & La Villa (no percibe diezmos) \\
\hline Fica & & & & $\begin{array}{l}\text { Compatrones de Munguía ( } 7 \\
\text { casas antiguas) }\end{array}$ \\
\hline Fica & & & & $\begin{array}{l}\text { El Cavildo y la Fábrica (llevan } \\
\text { los diezmos) }\end{array}$ \\
\hline Fica & & & & $\begin{array}{l}\text { Los vecinos (presentan los Be- } \\
\text { neficios) }\end{array}$ \\
\hline Forua & DIVISERO & 500 & 2721 & Conde de Montijo \\
\hline Forua & DIVISERO & 500 & & Viuda de Lope de Mazarredo \\
\hline Frúniz & REALENGO & & 2666 & $\begin{array}{l}\text { Condesa del Bado viuda de } \\
\text { Echauz }\end{array}$ \\
\hline Galdácano & REALENGO & & & Marqués de Rioflorido \\
\hline Galdames & REALENGO & & & Sr. Juan Escoiquiz \\
\hline Gámiz & & 60.4 & 0 & Diego de Colón \\
\hline Garai & DIVISERO & & & M. ${ }^{a}$ Josefa Villa-real de Verriz \\
\hline Garai & & & 4080 & Condesa de Mora \\
\hline Gatica & & 2775 & 6000 & Condesa de Mora \\
\hline Gatica & & & & $\begin{array}{l}\text { El Cabildo (lleva parte de diez- } \\
\text { mos) }\end{array}$ \\
\hline Gatica & & & & $\begin{array}{l}\text { El Patronato de Munguía (lleva } \\
\text { parte de diezmos) }\end{array}$ \\
\hline Gordejuela & & & & No tiene patrón. El Cabildo \\
\hline Górliz & REALENGO & & & $\begin{array}{l}\text { Condesa del Bado (acaba la } \\
\text { gracia con su muerte) }\end{array}$ \\
\hline Gorocica & DIVISERO & & 1024 & Condesa de Baños \\
\hline
\end{tabular}




\begin{tabular}{|c|c|c|c|c|}
\hline Iglesia & $\begin{array}{l}\text { Clase de } \\
\text { Patronato }\end{array}$ & $\begin{array}{l}\text { Prod. mens. } \\
\qquad 1834\end{array}$ & $\begin{array}{l}\text { Rend. } \\
1837\end{array}$ & Razón de Patronatos (1810) \\
\hline Guecho & DIVISERO & 3097 & & Marquesa de Villarías \\
\hline Guecho & DIVISERO & 556 & & Francisco de Mazarredo \\
\hline Gueñes & DIVISERO? & & & El Cabildo \\
\hline Gueñes & & 350 & & Don Jose Ramon de Salcedo \\
\hline Guernica & REALENGO & & & $\begin{array}{l}\text { El Cabildo (percibe diezmos y } \\
\text { presenta Beneficios) }\end{array}$ \\
\hline Guernica & REALENGO & & & $\begin{array}{l}\text { La Villa (no lleva diezmos ni } \\
\text { presenta Beneficios) }\end{array}$ \\
\hline Guernica & REALENGO & & & $\begin{array}{l}\text { Patronos de Luno y Arrazua } \\
\text { (parte de diezmos) }\end{array}$ \\
\hline Guerricaiz & & 387 & & La Prebostad \\
\hline Guerricaiz & & 80 & & Viuda de Lope de Mazarredo \\
\hline Guizaburuaga & & & & $\begin{array}{l}\text { Antonio Adan de Yarza (1/3 de } \\
\text { diezmos) }\end{array}$ \\
\hline Guizaburuaga & & & & $\begin{array}{l}\text { El Cabildo de Lequeitio ( } 2 / 3 \text { de } \\
\text { diezmos) }\end{array}$ \\
\hline $\begin{array}{l}\text { Guizaburuaga } \\
\text { Hermua }\end{array}$ & & 96 & & Juan José de Mugartegui \\
\hline Ibarranguelua & DIVISERO & 458 & & Antonio Adán de Yarza \\
\hline Ibarranguelua & DIVISERO & 520 & & Conde de Montijo \\
\hline Ibarranguelua & DIVISERO & & & $\begin{array}{l}\text { Francisco Antonio de Marugor- } \\
\text { ta (diezmo de } 1 \text { casa) }\end{array}$ \\
\hline Ibarranguelua & & & & Antonio Adán de Yarza (1/4) \\
\hline Ibarranguelua & & & & Baños $(1 / 4)$ \\
\hline Ibarranguelua & & & & El Estado (1/2) \\
\hline Ibarranguelua & & & & $\begin{array}{l}\text { Juan Antonio de Albiz (diezmo } \\
\text { de } 1 \text { casa) }\end{array}$ \\
\hline Ibarranguelua & & & & Conde de Montijo \\
\hline Ibarruri & REALENGO & & & Marqués de Monte hermoso \\
\hline Ibarruri & REALENGO & & & \\
\hline Izpaster & & & & $\begin{array}{l}\text { Antonio Adán de Yarza (pre- } \\
\text { voste) (1/3) }\end{array}$ \\
\hline Izpaster & & & & El Cabildo $(1 / 3)$ \\
\hline Izpaster & & & & La Fábrica $(1 / 3)$ \\
\hline Izurza & & & & El Párroco ( 2 casas) \\
\hline Izurza & & & & El Rey ( 1 casa) \\
\hline Izurza & DIVISERO & 1472 & 4000 & Juan Ramón de Arana \\
\hline Jemein & & 361 & 1231 & Conde de Peñaflorida \\
\hline Larrabezua & REALENGO & 3672 & & José Antonio de Romarate \\
\hline Larraur & & & 0 & \\
\hline Lauquíniz & & & 0 & Condesa de Mora \\
\hline Lejona & DIVISERO & & 0 & $\begin{array}{l}\text { Condesa de Mora (lleva diez- } \\
\text { mos y presenta Beneficios) }\end{array}$ \\
\hline
\end{tabular}




\begin{tabular}{|c|c|c|c|c|}
\hline Iglesia & $\begin{array}{l}\text { Clase de } \\
\text { Patronato }\end{array}$ & $\begin{array}{l}\text { Prod. mens. } \\
\qquad 1834\end{array}$ & $\begin{array}{l}\text { Rend. } \\
1837\end{array}$ & Razón de Patronatos (1810) \\
\hline Lejona & DIVISERO & 2250 & & Marquesa de Villarías \\
\hline Lemona & & 4100 & & Conde de Chinchón \\
\hline Lemóniz & REALENGO & 400 & 540 & Conde de Camarena \\
\hline Lequeitio & REALENGO & 1393 & 2400 & $\begin{array}{l}\text { Antonio Adán de Yarza (lleva } \\
\text { 1/3de diezmos) }\end{array}$ \\
\hline Lequeitio & REALENGO & & & $\begin{array}{l}\text { El Cabildo (presenta Beneficios } \\
\text { y lleva } 2 / 3 \text { dediezmos) }\end{array}$ \\
\hline Lequeitio & REALENGO & & & $\begin{array}{l}\text { La Villa (no lleva diezmos ni } \\
\text { presenta Beneficios) }\end{array}$ \\
\hline Lezama & & & & $\begin{array}{l}\text { Conde de Mora (presenta Be- } \\
\text { neficios y lleva } 132 \text { rs.) }\end{array}$ \\
\hline Lezama & & 1350 & & La Anteiglesia \\
\hline Lujua & DIVISERO & 300 & & Francisco Xabier de Batiz \\
\hline Luno & DIVISERO & 2750 & 5300 & Conde de Montefuerte \\
\hline Mallabia & REALENGO & & & Marqués de Rio-florido \\
\hline Mañaria & REALENGO & 2142 & & Conde de Ezpeleta \\
\hline Marquina & DIVISERO & 361 & & José Joaquín de Barroeta \\
\hline Marquina & DIVISERO & & & Casa de Ugarte (Marquina) (1/4) \\
\hline Marquina & DIVISERO & 723 & & La Villa de Marquina (la mitad) \\
\hline Maruri & DIVISERO & 438 & & Conde de Cancelada \\
\hline Maruri & DIVISERO & & & Conde de Mora \\
\hline Maruri & DIVISËRO & 658 & 1224 & $\begin{array}{l}\text { Gregorio de Lezama Leguiza- } \\
\text { món }\end{array}$ \\
\hline Maruri & DIVISERO & 200 & & Casa de Mendieta \\
\hline Mendata & REALENGO & 284 & 1000 & Conde de Peñaflorida \\
\hline Mendeja & & & & $\begin{array}{l}\text { Antonio Adan de Yarza (pre- } \\
\text { voste) (1/3) }\end{array}$ \\
\hline Mendeja & & & & El Cabildo $(1 / 3)$ \\
\hline Mendeja & & & & La Fábrica (1/3) \\
\hline Meñaca & & & 0 & Compatronos de Munguía \\
\hline Miravalles & $\begin{array}{l}\text { Pleito en } \\
\text { la Cámara }\end{array}$ & & & Valdecarzana \\
\hline Morga & DIVISERO & 2530 & 6000 & $\begin{array}{l}\text { Marqués de Valmediano (sólo- } \\
\text { presenta Beneficios) }\end{array}$ \\
\hline Mújica & & 2950 & & Condesa de Mora \\
\hline Mundaca & DIVISERO & & & $\begin{array}{l}\text { Condesa de Montijo (llevadora } \\
\text { de diezmos) }\end{array}$ \\
\hline Mundaca & & & & $\begin{array}{l}\text { El Cabildo (presenta los Bene- } \\
\text { ficios) }\end{array}$ \\
\hline Munguía & & 2603 & 2400 & $\begin{array}{l}52 \text { casas (llevan diezmos y } \\
\text { presentan Beneficios) }\end{array}$ \\
\hline Murélaga & & 2345 & 7808 & Condesa de Mora \\
\hline
\end{tabular}




\begin{tabular}{|c|c|c|c|c|}
\hline Iglesia & $\begin{array}{l}\text { Clase de } \\
\text { Patronato }\end{array}$ & $\begin{array}{l}\text { Prod. mens. } \\
\quad 1834\end{array}$ & $\begin{array}{l}\text { Rend. } \\
1837\end{array}$ & Razón de Patronatos (1810) \\
\hline Murélaga & & 488 & & Juan José de Mugartegui \\
\hline Murueta & & 800 & & La Anteiglesia \\
\hline Murueta & REALENGO & & & $\begin{array}{l}\text { Condesa viuda de Echauz (la } \\
\text { mitad) }\end{array}$ \\
\hline Murueta & DIVISERO & & & Don Manuel M.a de Urdaibai \\
\hline Nabárniz & DIVISERO & 2750 & 18460 & Condesa de Mora \\
\hline Nabárniz & DIVISERO & 2450 & & Conde de Montijo \\
\hline Nabárniz & DIVISERO & & & $\begin{array}{l}\text { Antonio Adán de Yarza (con } \\
\text { Ereño) }\end{array}$ \\
\hline Nabárniz & DIVISERO & 319 & & Juan José de Mugartegui \\
\hline Nabárniz & DIVISERO & 400 & & Olacua \\
\hline Nabárniz & DIVISERO & 400 & & Martín de Maguna \\
\hline Nachitua & DIVISERO & & & Condesa de Montijo \\
\hline Nachitua & DIVISERO & & & Don Antonio Adan \\
\hline Ochandiano & REALENGO & & & La Villa \\
\hline Ondárroa & REALENGO & & & El Cabildo \\
\hline Orduña & REALENGO & & 4080 & $\begin{array}{l}\text { El Cabildo (percibe diezmos y } \\
\text { presenta Beneficios) }\end{array}$ \\
\hline Orduña & REALENGO & & & La Ciudad \\
\hline Orozco & & & 3584 & Condesa de Coruña \\
\hline Orozco & DIVISERO & & 4400 & Don Jose Barcena \\
\hline Orozco & & & & Las Religiosas de Quejana \\
\hline Pedernales & REALENGO & & & $\begin{array}{l}\text { Don Nicolas de Antuñano (ha } \\
\text { pasado a la Corona) }\end{array}$ \\
\hline Plencia & REALENGO & & & $\begin{array}{l}\text { Condesa de Mora ( } 1 / 6 \text { de diez- } \\
\text { mos) }\end{array}$ \\
\hline Plencia & REALENGO & & & $\begin{array}{l}\text { El Cabildo ( } 1 / 6 \text { de diezmos y } \\
\text { presenta Beneficios) }\end{array}$ \\
\hline Plencia & REALENGO & & & La Fábrica (1/2) \\
\hline Plencia & REALENGO & & & La Villa (1/6 de diezmos) \\
\hline Portugalete & REALENGO & 3243 & & $\begin{array}{l}\text { Conde de Miranda (1/2 de } \\
\text { diezmos) }\end{array}$ \\
\hline Portugalete & REALENGO & & & $\begin{array}{l}\text { El Cabildo y la Fábrica ( } 1 / 2 \text { de } \\
\text { diezmos) }\end{array}$ \\
\hline Portugalete & REALENGO & & & $\begin{array}{l}\text { El Obispo de Santander (pre- } \\
\text { senta los Beneficios) }\end{array}$ \\
\hline Rigoitia & REALENGO & & & $\begin{array}{l}\text { Luis de Viguri (ha pasado a la } \\
\text { Corona) }\end{array}$ \\
\hline Echevarría & DIVISERO & 880 & & José Joaquín de Barroeta \\
\hline Echevarría & DIVISERO & & & $\begin{array}{l}\text { El Cabildo La Villa de Marqui- } \\
\text { nay la Colegiata de } C \text {. }\end{array}$ \\
\hline Echévarri & REALENGO & & & Marquesa de Río-Florido \\
\hline
\end{tabular}




\begin{tabular}{|c|c|c|c|c|}
\hline Iglesia & $\begin{array}{l}\text { Clase de } \\
\text { Patronato }\end{array}$ & $\begin{array}{l}\text { Prod. mens. } \\
\quad 1834\end{array}$ & $\begin{array}{l}\text { Rend. } \\
1837\end{array}$ & Razón de Patronatos (1810) \\
\hline Marzana & DIVISERO & 0 & & Iñigo Melchor Ortes de Velasco \\
\hline Barinaga & DIVISERO & & & $\begin{array}{l}\text { Casa de Barroeta (Marquina) } \\
(1 / 4)\end{array}$ \\
\hline Barinaga & DIVISERO & & & Casa de Ugarte (Marquina) (1/4) \\
\hline $\begin{array}{l}\text { Barinaga } \\
\text { Galdames }\end{array}$ & DIVISERO & & & La Villa de Marquina (la mitad) \\
\hline San Pelayo & & & 832 & $\begin{array}{l}\text { Conde de Camarena (con } \\
\text { Axpe Busturia) }\end{array}$ \\
\hline S.S. del Valle & & & & Conde de Miranda \\
\hline Santurce & REALENGO & & & $\begin{array}{l}\text { Conde de Miranda (1/2 de } \\
\text { diezmos) }\end{array}$ \\
\hline Santurce & REALENGO & & & $\begin{array}{l}\text { El Cabildo y la Fábrica }(1 / 2 \text { de } \\
\text { diezmos) }\end{array}$ \\
\hline Santurce & REALENGO & & & $\begin{array}{l}\text { El Obispo de Santander (pre- } \\
\text { senta los Beneficios) }\end{array}$ \\
\hline Sondica & DIVISERO & & & $\begin{array}{l}\text { Maria Cayetana de Castro } \\
(1 / 4)\end{array}$ \\
\hline Sondica & DIVISERO & 0 & & Marqués de Villarías \\
\hline Sondica & DIVISERO & & & Marqués de Bargas (1/4) \\
\hline Sopelana & DIVISERO & 1086 & 763 & Casa de Luyando \\
\hline Sopuerta & No hay patrono & & & El Cabildo \\
\hline Lamíndano & DIVISERO & & & Manuel María de Aldecoa \\
\hline Tres concejos & REALENGO & & & Conde de Miranda \\
\hline Trucíos & No hay patrono & 243 & 12000 & $\begin{array}{l}\text { Conde de Miranda (lleva diez- } \\
\text { mos) }\end{array}$ \\
\hline Trucios & \multicolumn{4}{|c|}{ Puente-hurtado (lleva diezmos) } \\
\hline Ubidea & \multicolumn{4}{|c|}{ No hay patrono } \\
\hline Urdúliz & DIVISERO & 864 & 883 & Marqués de Valmediano \\
\hline Vedia & REALENGO & & & Marqués de Rio-florido \\
\hline Vérriz & DIVISERO & 4616 & & Conde de Hervías \\
\hline Villaro & REALENGO & & & $\begin{array}{l}\text { El Beneficiado más antiguo } \\
\text { presenta Beneficios }\end{array}$ \\
\hline Villaro & REALENGO & & & La Villa \\
\hline Yurre & & & & Antonia de Aldecoa \\
\hline Yurre & & & & Domingo de Andicoechea \\
\hline Yurre & & & & Gregorio de Iriarriza \\
\hline Yurre & & & & Juan Alberto de Amezaga \\
\hline Yurre & & 2887 & 9180 & Condesa de Mora \\
\hline Yurre & & 400 & & Claudio Santos de Eguía \\
\hline Yurre & & & & Bartolomé M. ${ }^{\text {a de Labaien }}$ \\
\hline Yurre & & & & Joaquín de Ibargoitia \\
\hline Yurreta & REALENGO & & & Condesa de Mora \\
\hline
\end{tabular}




\begin{tabular}{|c|c|c|c|c|}
\hline Iglesia & $\begin{array}{l}\text { Clase de } \\
\text { Patronato }\end{array}$ & $\begin{array}{l}\text { Prod. mens. } \\
\quad 1834\end{array}$ & $\begin{array}{l}\text { Rend. } \\
1837\end{array}$ & Razón de Patronatos (1810) \\
\hline Yurreła & \multicolumn{3}{|l|}{ REALENGO } & Luis de Viguri \\
\hline Zaldíbar & REALENGO & 2000 & & Bernarda de Colón \\
\hline Zalla & \multirow{4}{*}{ No hay patrono } & 1340 & 4161 & Conde de Noblejas \\
\hline Zalla & & 557 & & José Ramón de Salcedo \\
\hline Zalla & & 557 & & Marqués de Bargas \\
\hline Zalla & & 557 & & Marqués de Legarda \\
\hline Zamudio & \multirow[t]{3}{*}{ DIVISERO } & 2805 & 3000 & Marqués de Malpica \\
\hline Zarátamo & & & & $\begin{array}{l}\text { El Señorío (era el Señor Ta- } \\
\text { ranco) }\end{array}$ \\
\hline Zollo & & & & $\begin{array}{l}\text { Pleito en la Cámara } 60 \text { Con- } \\
\text { desa de Mora }\end{array}$ \\
\hline \multicolumn{3}{|c|}{ Rendim. Mensual la mitad } & \multicolumn{2}{|l|}{150.324} \\
\hline \multicolumn{2}{|c|}{ Rendimiento anual } & 3.607 .776 & 259.543 & \\
\hline
\end{tabular}

\section{ANEXO II}

\section{PATRONOS DE LAS IGLESIAS DE VIZCAYA Y SUS RENTAS EN 1834}

Las fuentes son las mismas que las del Anexo I. Hay que tener en cuenta que los rendimientos mensuales que fueron evaluados por los patronos para la contribución extraordinaria solicitada por la Diputación en Circular de 4 de marzo de 1834 (AFB-A, ORGFB, Caja 158) fueron reducidos a la mitad. También se debe tener en cuenta que en la presente relación no se han incluido los patronatos que la Diputación disfruta en virtud de la Real Orden de 16 de marzo de 1808 para el Establecimiento de niños expósitos: «La comisión ha partido del principio sentado por la Junta de Subsistencias, y adoptado en la citada de patronos de reducir sus capitales a la mitad; mas debe observar que no ha bajado el tanto por ciento de administración, y los reparos y obras que se ofrecen en las iglesias, que son de mucha entidad como consta a V.S.I. siendo así que estos objetos parece que se tuvieron en consideración al formar la estadística territorial. No se han incluido los patronatos que la Diputación disfruta por Rl. Merced, en consideración a estar sus productos consignados a los niños expósitos y que se necesitará extraer de la Caja general lo que por este lado se le exigiese...» (AFB-A, CC, Reg. 15, leg. 5). 


\begin{tabular}{|c|c|c|c|}
\hline Rarón de Patronatos (1810) & Iglesia & $\begin{array}{l}1 / 2 \text { prod. } \\
\text { mens. } 1834\end{array}$ & $\begin{array}{c}\text { prdto. Anual } \\
\text { (rs.vn.) }\end{array}$ \\
\hline 52 casas & Munguía & 2603 & 62472 \\
\hline Alvarado y Cevallo & Carranza & 560 & 13440 \\
\hline Antonio Adán de Yarza & Ereño & 3413 & 81912 \\
\hline Antonio Adán de Yarza & Ibarranguelua & 458 & 10992 \\
\hline Antonio Adán de Yarza & Lequeitio & 1393 & 33432 \\
\hline Bernarda de Colón & Zaldíbar & 2000 & 48000 \\
\hline Casa de Luyando & Sopelana & 1086 & 26064 \\
\hline Casa de Mendieta & Maruri & 200 & 4800 \\
\hline Claudio Santos de Eguía & Yurre & 400 & 9600 \\
\hline Conde de Camarena & Axpe de Busturia & 3239 & 77736 \\
\hline Conde de Camarena & Lemóniz & 400 & 9600 \\
\hline Conde de Cancelada & Cortezubi & 3604 & 86496 \\
\hline Conde de Cancelada & Maruri & 438 & 10512 \\
\hline Conde de Corres & Baracaldo & 550 & 13200 \\
\hline Conde de Chinchón & Lemona & 4100 & 98400 \\
\hline Conde de Ezpeleta & Mañaria & 2142 & 51408 \\
\hline Conde de Hervías & Vérriz & 4616 & 110784 \\
\hline Conde de Miranda & Arcentales & 3083 & 73992 \\
\hline Conde de Miranda & Portugalete & 3243 & 77832 \\
\hline Conde de Miranda & Trucíos & 243 & 5832 \\
\hline Conde de Montefuerte & Luno & 2750 & 66000 \\
\hline Conde de Montijo & Arrazua & 2.200 & 52800 \\
\hline Conde de Montijo & Arteaga & 3115 & 74760 \\
\hline Conde de Montijo & Echano & 825 & 19800 \\
\hline Conde de Montijo & Forua & 500 & 12000 \\
\hline Conde de Montijo & Ibarranguelua & 520 & 12480 \\
\hline Conde de Montijo & Nabárniz & 2450 & 58800 \\
\hline Conde de Noblejas & Zalla & 1340 & 32160 \\
\hline Conde de Peñaflorida & Jemein & 361 & 8664 \\
\hline Conde de Peñaflorida & Mendata & 284 & 6816 \\
\hline Conde de Villafuente & Carranza & 560 & 13440 \\
\hline Condesa de Mora & Abadiano & 5709 & 137016 \\
\hline Condesa de Mora & Aránzazu & 200 & 4800 \\
\hline Condesa de Mora & Arrancudiaga & 1100 & 26400 \\
\hline Condesa de Mora & Arrieta & 160 & 3840 \\
\hline Condesa de Mora & Berango & 500 & 12000 \\
\hline Condesa de Mora & Erandio & 6400 & 153600 \\
\hline Condesa de Mora & Gatica & 2775 & 66600 \\
\hline
\end{tabular}




\begin{tabular}{|c|c|c|c|}
\hline Rarón de Patronatos (1810) & Iglesia & $\begin{array}{l}1 / 2 \text { prod. } \\
\text { mens. } 1834\end{array}$ & $\begin{array}{c}\text { prdto. Anual } \\
\text { (rs.vn.) }\end{array}$ \\
\hline Condesa de Mora & Mújica & 2950 & 70800 \\
\hline Condesa de Mora & Murélaga & 2345 & 56280 \\
\hline Condesa de Mora & Nabárniz & 2750 & 66000 \\
\hline Condesa de Mora & Yurre & 2887 & 69288 \\
\hline Condesa de Mora & Zollo & 60 & 1440 \\
\hline Diego de Arriola & Ceánuri & 5690 & 136560 \\
\hline Diego de Colón & Gámiz & 604 & 14496 \\
\hline El Mayordomo de la Fábrica & Ajánguiz & 4000 & 96000 \\
\hline Eulogio de Larrinaga & Arbácegui & 1080 & 25920 \\
\hline Felipe de Trevilla & Carranza & 560 & 13440 \\
\hline Francisco de Mazarredo & Guecho & 556 & 13344 \\
\hline Francisco Domingo de Chabarri & Baracaldo & 550 & 13200 \\
\hline Francisco Xabier de Batiz & Lujua & 300 & 7200 \\
\hline Gregorio de Lezama & Leguizamón Maruri & 658 & 15792 \\
\hline Ignacio M. a Sanchez de Vicuña & Castillo y Elejaveitia & 459 & 11016 \\
\hline Iñigo Melchor Ortes de Velasco & Axpe de Arrázola & 1500 & 36000 \\
\hline Joaquin Hurtado de Mendoza & Arcentales & 665 & 15960 \\
\hline José Antonio de Echevarría & Axpe de Busturia & 178 & 4272 \\
\hline José Antonio de Romarate & Carranza & 560 & 13440 \\
\hline José Antonio de Romarate & Larrabezua & 3672 & 88128 \\
\hline José joaquín de Barroeta & Echevarría & 880 & 21120 \\
\hline José Joaquín de Barroeta & Marquina & 361 & 8664 \\
\hline Jose Ramon de Salcedo & Gueñes & 350 & 8400 \\
\hline José Ramón de Salcedo & Zalla & 557 & 13368 \\
\hline Juan José de Mugartegui & Guizaburuaga & 96 & 2304 \\
\hline Juan José de Mugartegui & Murélaga & 488 & 11712 \\
\hline Juan José de Mugartegui & Nabárniz & 319 & 7656 \\
\hline Juan Ramón de Arana & Izurza & 1472 & 35328 \\
\hline La Anteiglesia & Lezama & 1350 & 32400 \\
\hline La Anteiglesia & Murueta & 800 & 19200 \\
\hline La Prebostad & Guerricaiz & 387 & 9288 \\
\hline La Villa de Marquina & Marquina & 723 & 17352 \\
\hline Los Cabildos & Amorebieta & 3850 & 92400 \\
\hline Lucas de Urrecha & Castillo y Elejaveitia & 731 & 17544 \\
\hline Mariano de Castaños & Baracaldo & 550 & 13200 \\
\hline Marqués de Bargas & Begoña & 2170 & 52080 \\
\hline Marqués de Bargas & Zalla & 557 & 13368 \\
\hline Marqués de Legarda & Zalla & 557 & 13368 \\
\hline
\end{tabular}




\begin{tabular}{|c|c|c|c|}
\hline Rarón de Patronatos (1810) & Iglesia & $\begin{array}{c}1 / 2 \text { prod. } \\
\text { mens. } 1834\end{array}$ & $\begin{array}{l}\text { prdto. Anual } \\
\text { (rs.vn.) }\end{array}$ \\
\hline Marqués de Llano & Dima & 4435 & 106440 \\
\hline Marqués de Malpica & Zamudio & 2805 & 67320 \\
\hline Marqués de Valmediano & Baracaldo & 550 & 13200 \\
\hline Marqués de Valmediano & Morga & 2530 & 60720 \\
\hline Marqués de Valmediano & Urdúliz & 864 & 20736 \\
\hline Marquesa de Villarías & Abando & 1650 & 39600 \\
\hline Marquesa de Villarías & Guecho & 3097 & 74328 \\
\hline Marquesa de Villarías & Lejona & 2250 & 54000 \\
\hline Martín de Maguna & Nabárniz & 400 & 9600 \\
\hline Melquiades María de Goya & Ceánuri & 187 & 4488 \\
\hline Olacua & Nabárniz & 400 & 9600 \\
\hline Pedro de Meñaca Batiz & Arrieta & 400 & 9600 \\
\hline Saturnino Salazar & Baracaldo & 550 & 13200 \\
\hline \multicolumn{4}{|l|}{ Vecinos de la parcialidad } \\
\hline «Patrona del Valle» & Ceberio & 4582 & 109968 \\
\hline Viuda de Lope de Mazarredo & Arrieta & 1600 & 38400 \\
\hline Viuda de Lope de Mazarredo & Baracaldo & 550 & 13200 \\
\hline \multirow[t]{2}{*}{ Viuda de Lope de Mazarredo } & Bermeo casa & & \\
\hline & de Trivis & 75 & 1800 \\
\hline Viuda de Lope de Mazarredo & Carranza & 560 & 13440 \\
\hline Viuda de Lope de Mazarredo & Cuatro concejos & 4517 & 108408 \\
\hline Viuda de Lope de Mazarredo & Forua & 500 & 12000 \\
\hline Viuda de Lope de Mazarredo & Guerricaiz & 80 & 1920 \\
\hline Rendimientos totales & & 150.324 & 3.607 .776 \\
\hline
\end{tabular}

\section{ANEXO III}

\section{PATRONATOS DE LA DIPUTACION DE VIZCAYA EN 1834}

De los informes sobre Patronatos Realengos emitidos como consecuencia de la solicitud de la Real Cámara remitida a la Diputación de Vizcaya en fecha 31 de agosto de 1767 (AFB-A, PA, Reg 1, leg. 3) y de los repartos para la contribución del $4 \%$ de 1834 , se puede deducir que en tal fecha los Patronatos Realengos que ya habían sido traspasados a la Diputación para el sostenimiento del Establecimiento de Expósitos, que había sido concedido por R.O. de 16 de marzo de 1808, son los siguientes: 


\begin{tabular}{|c|c|c|}
\hline Iglesia & Úlitimo perceptor & Título de merced Real \\
\hline San Salvador de Frúniz & Luis Josef de Sarría & 19 de marzode 1765 \\
\hline Santa María de Górliz & Luis Josef de Sarría & 19 de marzo de 1765 \\
\hline Santa María de Albóniga & Luis Josef de Sarría & 19 de marzo de 1765 \\
\hline Santa M. ${ }^{\text {a }}$ de Basigo de Baquio & Luis Josef de Sarría & 19 de marzo de 1765 \\
\hline Arrigorriaga & Marqués de Mejorada & $\begin{array}{l}13 \text { de diciembre de } 1721 \\
\text { (por4 vidas) }\end{array}$ \\
\hline Basauri & Marqués de Mejorada & \\
\hline San Llorente de Zarátamo & M. a Manuela de Recalde & 22de junio de 1722 \\
\hline San Andrés de Pedernales & Enrique de Badia & 22 de junio de 1766 \\
\hline Irubalzaga de Rigoitia & Conde de Moriana & 26 de enero de 1741 \\
\hline San Cristobal de Derio & Conde de Moriana & 27 de enero de 1741 \\
\hline San Miguel de Yurreta & Conde de Moriana & 2 de febrero de 1747 \\
\hline Elorrio & Marqués de Montehermoso & 22 de enero de 1764 \\
\hline Ibarruri & Marqués de Montehermoso & 22 de enero de 1764 \\
\hline Galdácano & M. ${ }^{\text {a Josefa de Ordeñana }}$ & 3 de julio de 1749 \\
\hline Mallavia & M. a Josefa de Ordeñana & 3 de julio de 1749 \\
\hline Echévarri & M.a Josefa de Ordeñana & 3 de julio de 1749 \\
\hline
\end{tabular}

